\title{
MODERN MOVEMENTS OF THE CRUST SURFACE IN GORNY ALTAI FROM GPS DATA
}

\author{
V. Yu. Timofeev, D. G. Ardyukov, A. V. Timofeev, E. V. Boiko
}

\begin{abstract}
In 2000-2017, the GPS technology was first applied to study inter-seismic, co-seismic and post-seismic processes in the crust of the Altai Mountains (Gorny Altai). Our study aims at investigating the fields of displacement and deformation in the Gorny Altai region as a part of Asia. The 3D displacement fields are reconstructed for the period before the M 7.3 Chuya earthquake that occurred in the southern sector of the Altai GPS network $\left(49^{\circ}\right.$ to $55^{\circ} \mathrm{N}$, and $81^{\circ}$ to $89^{\circ} \mathrm{E}$ ) on 27 September 2003 . Anomalous behavior features are discovered in the displacement orientations, as well as in the distribution of velocities and deformation in the zone of the future earthquake. The spatial displacement pattern defined for the period of co-seismic displacements corresponds to the right-lateral strike-slip along the vertical fault. The fault depth is estimated using the elastic model and the experimental data (change in displacement from $0.30 \mathrm{~m}$ to $0.02 \mathrm{~m}$ at the distances of $14 \mathrm{~km}$ and $84 \mathrm{~km}$ from the fault, respectively); it amounts to $8-10 \mathrm{~km}$. The coseismic deformation field is investigated. In the post-seismic stage (2004-2017), displacements revealed in the epicentral zone show the right-lateral strike-slip along the fault at the rate of $2 \mathrm{~mm} / \mathrm{yr}$. Therefore, two-layer viscoelastic models can be considered. The estimated viscosity of the lower crust ranges from $6 \cdot 10^{19}$ to $3 \cdot 10^{20} \mathrm{~Pa} \cdot \mathrm{s}$, and the elastic upper crust thickness is $25 \mathrm{~km}$. Analyzed are modern movements in the Gorny Altai region outside the Chuya earthquake area. The results of our study show that modern horizontal displacements occur in the NNW direction at the rate of $1.1 \mathrm{~mm} / \mathrm{yr}$, which is twice lower than the displacement rate before the earthquake.
\end{abstract}

Key words: space geodesy; GPS; earth crust; Gorny Altai; inter-seismic, coseismic and post-seismic displacements; linear rheology; elastic and viscoelastic models 


\title{
СОВРЕМЕННЫЕ ДВИЖЕНИЯ ЗЕМНОЙ ПОВЕРХНОСТИ ГОРНОГО АЛТАЯ ПО GPS-НАБЛЮДЕНИЯМ
}

\author{
В. Ю. Тимофеев, Д. Г. Ардюков, А. В. Тимофеев, Е. В. Бойко \\ Институт нефтегазовой геологии и геофизики им. А.А. Трофимука СО РАН, Новосибирск, Россия
}

\begin{abstract}
Аннотация: Технология космической геодезии впервые использована для изучения межсейсмических, косейсмических и постсейсмических процессов в земной коре Горного Алтая с 2000 по 2017 г. Показано место Горного Алтая в полях смещений и деформаций Азии. Получены поля 3D смещений перед Чуйским землетрясением (27.09.2003 г., M=7.3), произошедшим в южной части Алтайской GPS-сети (от $49^{\circ}$ до $55^{\circ}$ с.ш. и от $81^{\circ}$ до $89^{\circ}$ в.д.). Выделено аномальное поведение в ориентации смещений, в распределении скоростей и деформаций в зоне будущего землетрясения. В эпоху косейсмических смещений получено распределение смещений, соответствующее правостороннему сдвигу на вертикальном разрыве. С использованием экспериментальных данных (изменение смещения от 0.3 м в 14 км от разрыва до 0.02 м в 84 км) и упругой модели получена оценка глубины разрыва (8-10 км). Исследовано поле косейсмических деформаций. Для постсейсмического этапа (2004-2017 гг.) выделяются смещения в эпицентральной зоне. Они повторяют правостороннее движение (скорость 2 мм/год) на разрыве, что позволило рассмотреть двухслойные вязкоупругие модели, оценить вязкость нижней коры $\left(6 \cdot 10^{19}-3 \cdot 10^{20}\right.$ Па·c) и мощность упругой верхней (25 км). Проанализированы современные движения Горного Алтая вне области Чуйского землетрясения. Величина современных горизонтальных смещений составила 1.1 мм/год при направлении на ССЗ $\left(-30^{\circ}\right)$. Скорость смещения оказалась более чем в два раза меньше значений скоростей перед землетрясением.
\end{abstract}

Ключевые слова: космическая геодезия; земная кора; Горный Алтай; межсейсмические, косейсмические и постсейсмические смещения; линейная реология; упругие и вязкоупругие модели

\section{1. ВВЕДЕНИЕ}

Предметом нашего исследования являются современные движения Горного Алтая. Задачи работы - изучение природы современных движений, их связь со смещениями Азии и сейсмичностью региона. Исследуемый регион является одним из наиболее контрастных по формам рельефа в Сибири. Он включает южную окраину стабильной Западно-Сибирской плиты (высота 120 м), ряд низкогорных складчатых сооружений (Томь-Колыванская зона, Салаир, Кузнецкий Алатау) и молодую горную систему - Горный Алтай, в пределах которой расположена самая высокая вершина Сибири (г. Белуха, высота 4506 м). Горообразовательные движения в Горном Алтае активно продолжаются в последние 5-10 млн лет. Результат этих движений можно наблюдать в резкопересеченном рельефе, наличии глубоких речных долин, горных плато на высоте 2000-3000 м и хребтов с высотой 3000$4000 \mathrm{M}$.

Высокоточные измерения современных смещений земной поверхности в настоящее время в основном проводятся методами космической геодезии. Такие исследования в мире с использованием технологии GPS развиваются с начала 90-х годов прошлого столетия. В Горном Алтае эти работы начаты в 2000 г., охватывают эпохи перед Чуйским землетрясением (27.09.2003 г., $\mathrm{M}=7.3,50.0^{\circ}$ с.ш., $88.1^{\circ}$ в.д.), в момент землетрясения и после него. Алтайская геодинамическая сеть, простирающаяся от Новосибирска до монгольской границы, охватывает территорию от $49^{\circ}$ до $55^{\circ}$ с.ш. и от $81^{\circ}$ до $89^{\circ}$ в.д. и включает структурные элементы Горного Алтая и его окружения (рис. 1). Через 15 лет после Чуйского землетрясения можно сделать некоторые выводы об особенностях сейсмического процесса в регионе. Проанализируем ситуацию по отдельным эпохам, рассматривая данные, полученные с 2000 по 2017 г. Проведем пошаговую интерпретацию отдельно для межсейсмических, косейсмических и постсейсмических процессов.

\section{2. ТЕХНОЛОГИЯ ПОЛУЧЕНИЯ ДАННЫХ О СМЕЩЕНИЯХ}

Определение смещений пунктов геодинамической сети Горного Алтая проводилось по данным ежегодной GPS-съемки. Данные получены с помощью приемников TRIMBLE-4700, в основном на скальных реперах на 2-3 суточных сериях. Измерения проводились ежегодно в июле - августе. 


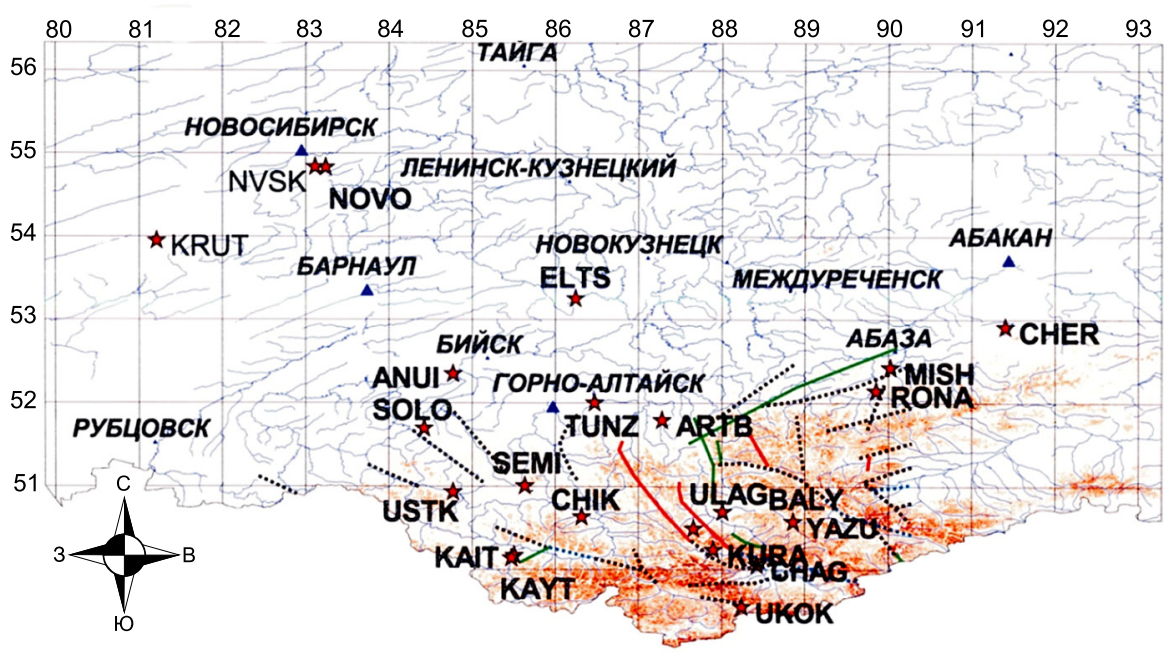

Рис. 1. Алтае-Саянская геодинамическая сеть космической геодезии ИНГГ CO РАН. Пункты GPS-наблюдений отмечены звездочками и кодами пунктов, треугольниками показаны областные центры. Сеть заложена в 2000 г., дополнена в 2001 и 2004 гг. Всего 25 пунктов. Сплошные и пунктирные линии - сеть разломов по комплексу геологических данных. Голубыми линиями показана гидросеть.

Fig. 1. The Altai-Sayan geodynamic network of GPS measurements (Trofimuk Institute of Petroleum Geology and Geophysics SB RAS). The network was launched in 2000 and extended in 2001 and 2004 (25 stations). Stars - locations of GPS observation stations and their codes; triangles - cities; solid and dashed lines - network of faults detected from the geological data. Blue lines - network of water bodies.

Обработка данных велась с помощью пакета GAMIT/GLOBK [Herring et al., 2006a, 2006b]. GAMIT это коллекция программ обработки фазовых данных для оценки трехмерных относительных координат наземных станций, орбит спутников, атмосферной зенитной задержки и параметров ориентации Земли. Пакет разработан для работы на любой UNIX-подобной операционной системе (в нашем случае на OC Linux RedHat 7.2 и Ubuntu 14). Для вычисления значений скоростей применялась следующая методика. Параметры трансформации геодезических систем координат, орбит спутников и ориентации Земли, лунные и солнечные эфемериды, данные о нутации и вращении полюса Земли, океанических приливах, временных задержках UT1, а также характеристики антенн GPS-приемников, точные эфемериды орбит спутников взяты из международной сети IGS (скачивание этих данных осуществлялось с серверов хранения и обработки данных сети IGS, таких как SOPAC). Ежесуточные комбинированные решения по всем мировым станциям сети IGS также взяты с серверов SOPAC и MIT. Главная часть - экспериментальные данные измерений методом GPS, получены нами при проведении полевых экспедиций по Алтае-Саянской геодинамической сети. Обсчет массива данных проводится программным модулем GAMIT по методике расчета совместных измерений по сети, с уравниванием по методу наименьших квадратов. На выходе получаем точные значения координат стан- ций в системе ITRF2000 для каждого дня эксперимента. Далее для получения поля скоростей полученные значения координат станций обрабатываются совместно с комбинированными общемировыми сетевыми решениями в модуле GLOBK. GLOBK является реализацией фильтра Калмана, основная цель работы которого - комбинирование различных геодезических решений. Принимается, что данные, или «квазинаблюдения», оцениваются, и из анализа наблюдений создается ковариационная матрица, включающая в себя координаты станции, параметры ориентации Земли, орбитальные параметры, исходную позицию станции. Входные решения обычно выполнены с изначальными неопределенностями во всех глобальных параметрах, так что поправки могут быть использованы для коррекции в комбинированном решении. Рассматриваемые в работе сетевые решения обычно включали в себя параметры для станций геодинамической сети Алтая (15-20 пунктов с опросом от 2 до 10 дней) и параметры постоянных станций Евразии (20-30 станций с представительностью, по возможности, на весь период ежегодного опроса - 30 суток непрерывных наблюдений). В этом случае по одной эпохе (например, 2000-2001 гг.) получаем для горизонтальных скоростей ошибку 2.0-2.5 мм. Счет, включающий две эпохи, приводит к ошибке определения горизонтальных скоростей 0.9-1.3 мм, для вертикальных - 3.7-4.9 мм; три эпохи - 0.6-0.9 и 2.4-3.3 мм. При увеличении количества эпох 


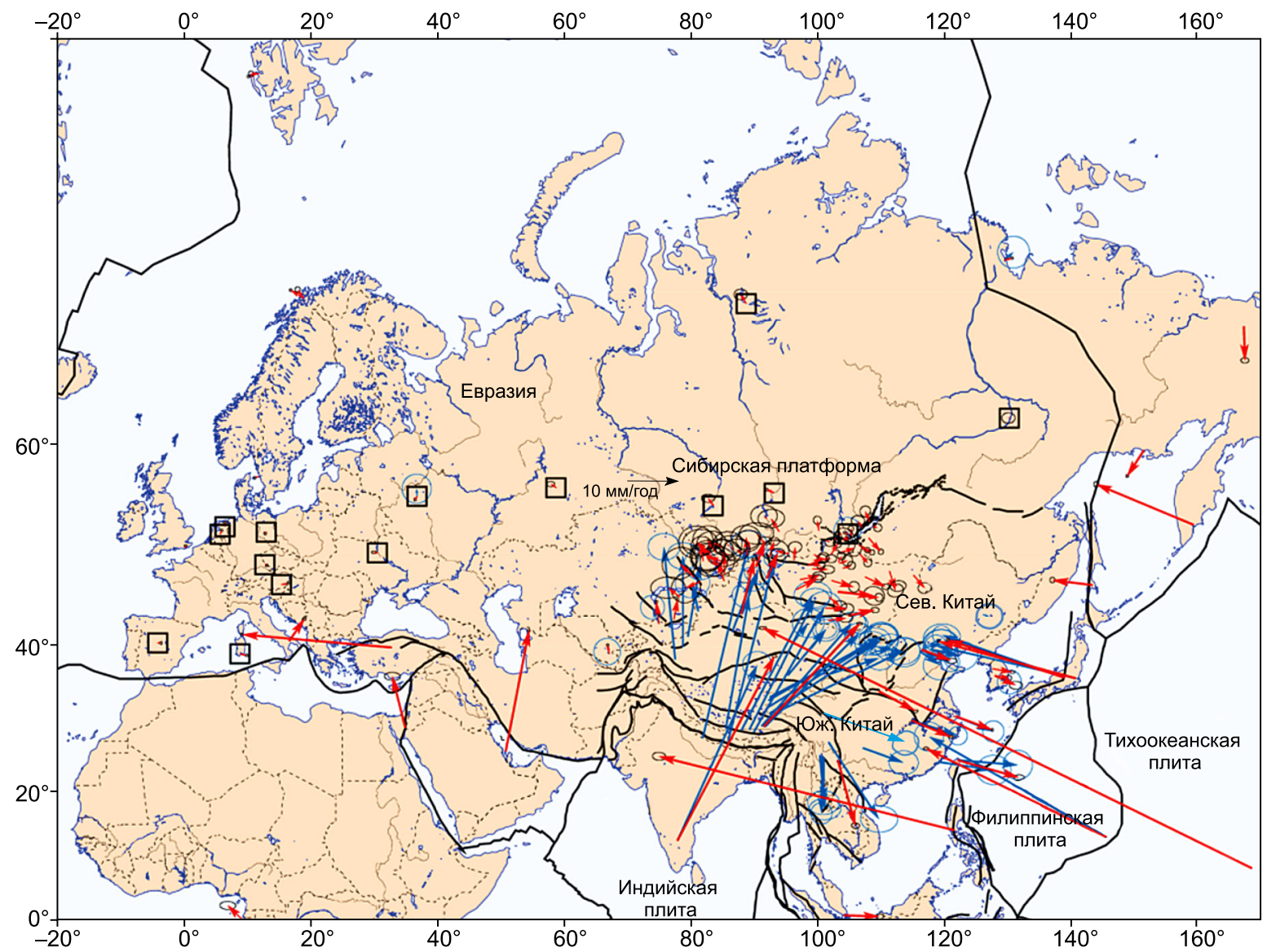

Рис. 2. Поле скоростей горизонтальных смещений относительно Евразийской плиты по данным GPS-измерений на постоянных станциях сети IGS (1992-2002 гг.). Квадратами отмечены базовые станции в северной недеформируемой части Евразии, относительно которых проводился счет: MADR, CAGL, KOSG, WSRT, POTS, WTZT, GRAZ, GLSV, MOBN, ARTU, NVSK, IRKT, KSTU, NRIL, YAKT. Эллипсы погрешностей показаны с доверительным интервалом 95 \% [Calais et al., 2002a].

Fig. 2. The field of horizontal displacement rates with respect to the Eurasian plate. The estimations are based on the GPS measurements provided by the IGS network of permanent stations (1992-2002). Squares - base stations in the northern non-deformed part of Eurasia, which are taken as reference points for calculations (MADR, CAGL, KOSG, WSRT, POTS, WTZT, GRAZ, GLSV, MOBN, ARTU, NVSK, IRKT, KSTU, NRIL, and YAKT]. 95 \% error ellipses [Calais et al., 2002a].

наблюдений до 4-5 ошибка уменьшается до 0.30.4 мм, при этом ошибка для вертикальных скоростей в 3-4 раза превышает горизонтальную ошибку [Goldin et al., 2005]. Увеличение времени записи на пункте до 1 месяца уменьшает ошибку в 2 раза и более.

\section{3. СИТУАЦИЯ ПЕРЕД ЗЕМЛЕТРЯСЕНИЕМ (2000-2003 ГГ.)}

Движения земной коры на юге Сибири связаны с современными процессами в Азии. Рассмотрим поле смещений для Евразии и ее окружения. Вычисления проводились по данным, полученным до 2002 г., относительно постоянных станций севера Евразии (рис. 2).

Сводная картина получена по различным источникам [Calais et al., 2002a]. Как видим из результа- тов, явно проявляется движение Индийской плиты на ССВ (45 мм/год) (рис. 2) и деформирование южной части Азии с постепенным уменьшением скорости на север. Значение скорости деформации по линии север-юг составляет 0.7 мм на градус широты в год или $6 \cdot 10^{-9}$ в год или $2 \cdot 10^{-16} \mathrm{c}^{-1}$. Полученный эффект и его величина, возможно, отражают течение вещества литосферы Азии в северном направлении от зоны контакта Индийской плиты до Сибирской платформы, где скорости уменьшаются до нуля. Изменение деформации в южной части Азии показаны на рис. 3 [Calais et al., 2002a, 2006]. Северозападная часть поля деформаций отличается низким уровнем доверительного интервала (уровень $67 \%$ отмечен белым цветом на рисунке), что показывает актуальность исследований в АлтаеСаянской области. Результаты измерений на постоянных станциях системы IGS (Международный 


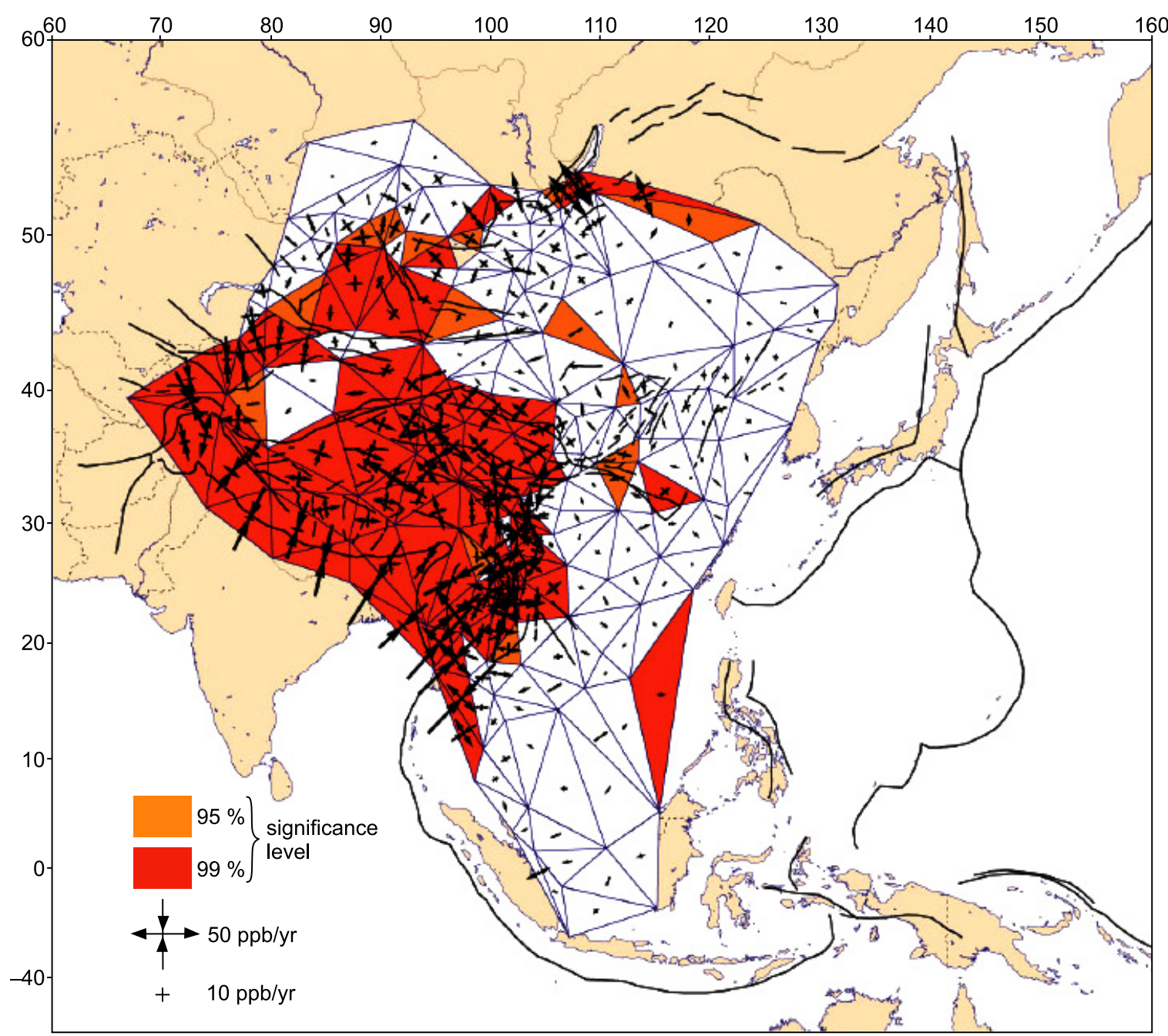

Рис. 3. Поле деформаций для деформируемой части Азии, построенное по данным космической геодезии до 2005 г. Показаны результаты с доверительным интервалом 99 \%, 95 \% и ниже (67 \% - показаны белым цветом). Величина скорости деформации за год: 50·10-9, 10·10-9 [Calais et al., 2002a, 2006].

Fig. 3. The deformation field reconstructed for the deformed part of Asia from the GPS data before the year of 2005 . Confidence intervals of $99 \%, 95 \%$ and below (67 \% - white). Annual deformation rates: 50.10-9 $10^{-10^{-9}}$ [Calais et al., 2002a, 2006].

центр по геодинамике) позволяют определить ориентацию и величину годового изменения главных деформаций центральной части Азии. Как представлено на рис. 4, Горный Алтай находится в состоянии стесненного сжатия с максимальной скоростью $-7.4 \cdot 10^{-9}$ в год по направлению N9² практически на север. Анализ данных, полученных с 2000 г. до середины 2003 г. по алтайской сети, показывает, что в эту эпоху в южной части Горного Алтая движение на север распадается на северозападное и северо-восточное (рис. 5). Скорости смещения пунктов алтайской сети относительно Евроазиатской тектонической плиты за период 2000-2003 гг. представлены в табл. 1.

Наиболее точные результаты получены на продолжительных периодах измерений (20002003 гг.) на скальных реперах. Использование жесткой центровки антенн позволило рассматривать как горизонтальные, так и вертикальные скорости смещений. Как показано на рис. 5 и в табл. 1, скорости смещений имеют различную ориентацию. Так, в западной части Горного Алтая зарегистрированы смещения на северо-запад, здесь скорость в среднем составила 2.6 мм/год. В восточной части Горного Алтая выделены смещения на севервосток, при скорости от 11 до 2 мм/год. Аномалии в поле скоростей перед землетрясением - это два доминирующих направления смещений (C3 и СВ) на юге региона, где происходит резкий поворот векторов скоростей в области будущих эпицентров Чуйского землетрясения и его афтершоков. В южной части (вблизи монгольской границы) северовосточное направление скоростей согласуется с направлением движений на CCB по GPS-данным 
V.Yu. Timofeev et al.: Modern movements of the crust surface in Gorny Altai...

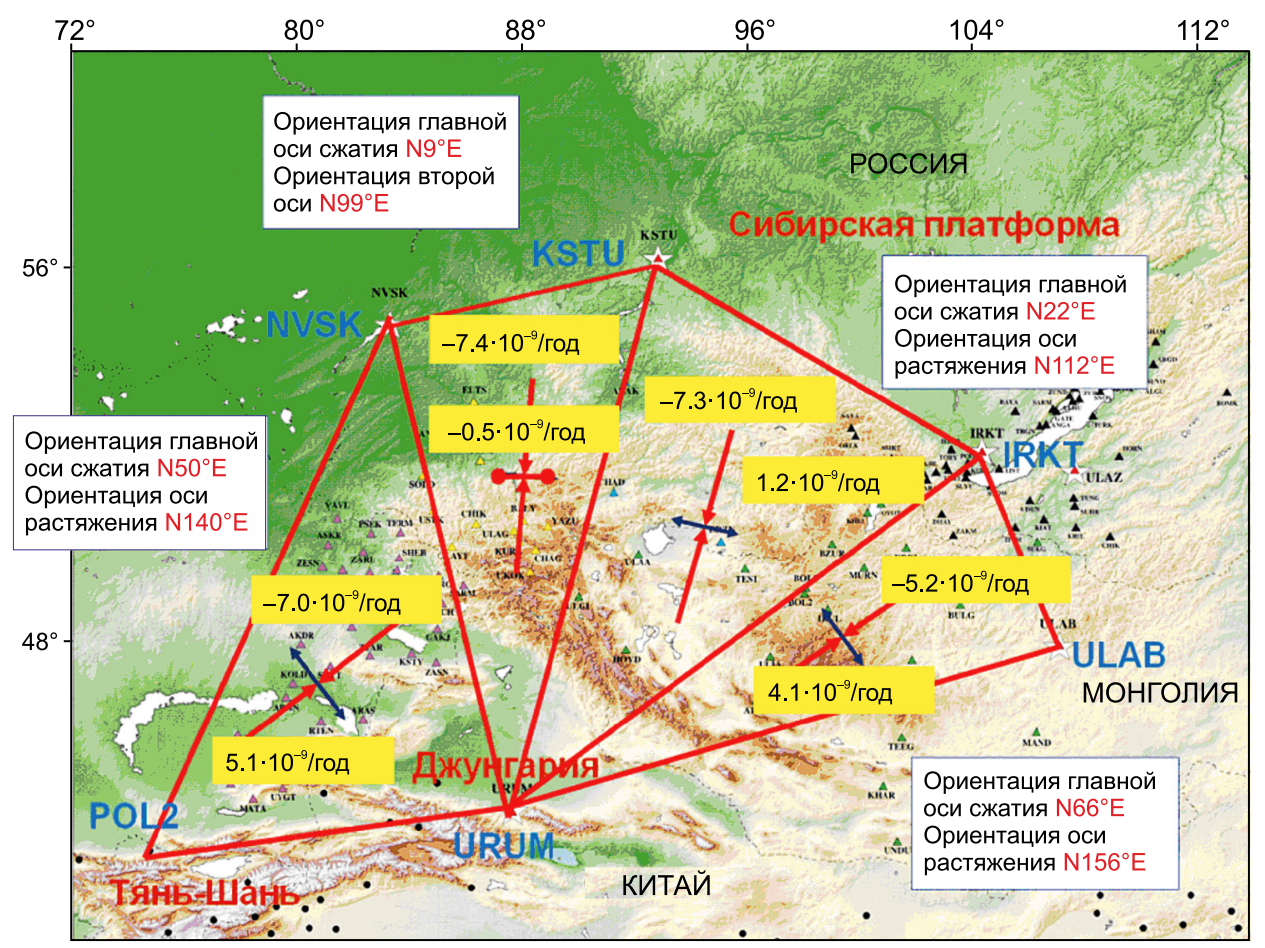

Рис. 4. Ориентация и скорости деформирования для центральной части Азии по данным измерений на постоянных станциях сети IGS (1995-2003 гг.).

Fig. 4. Deformation orientations and rates for the central part of Asia. The estimations are based on the GPS measurements provided by the IGS network of permanent stations (1995-2003).

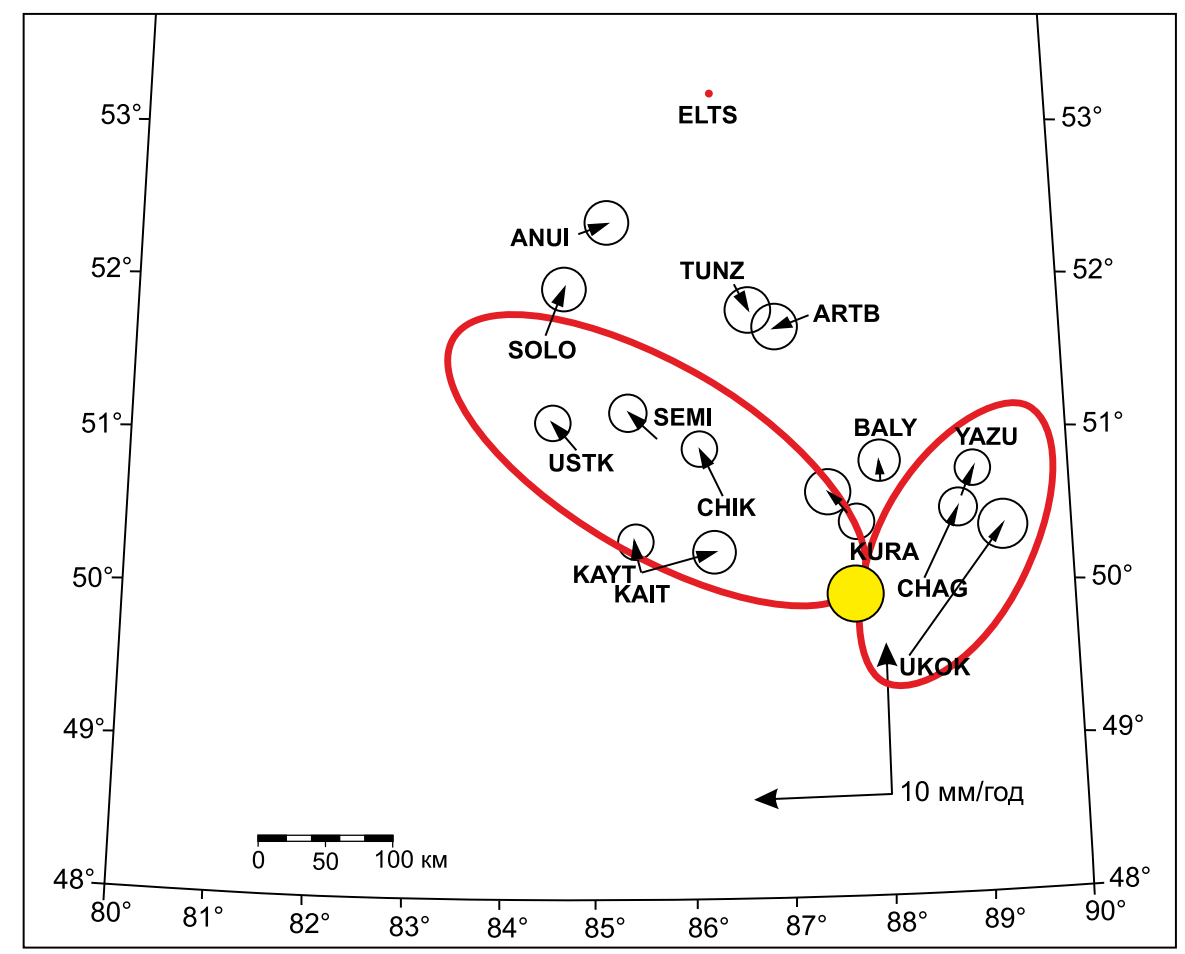

Рис. 5. Поле скоростей горизонтальных смещений Горного Алтая относительно Евразийской плиты по ежегодным измерениям с 2000 по 2003 г. Кружком показано положение эпицентра будущего Чуйского землетрясения 27 сентября 2003 г. Пункт ELTS расположен на равнине севернее Горного Алтая.

Fig. 5. The field of horizontal displacement rates for the Gorny Altai region with respect to the Eurasian plate. The estimations are based on the measurements taken in 2000-2003. Circle - epicenter of the future Chuya earthquake (27 September 2003). Station ELTS is located on the plain north of the Altai Mountains. 
Т а б л и ц а 1. Скорости смещений по ежегодным измерениям в эпоху 2000-2003 гг. перед Чуйским землетрясением 27.09.2003 г. относительно северной части Евразийской плиты

$\mathrm{T}$ a b l e 1. Displacement rates calculated from the annual measurements taken in 2000-2003 before the 27.09.2003 Chuya earthquake, relative to the northern part of the Eurasian plate

\begin{tabular}{|c|c|c|c|c|c|}
\hline Код и тип пункта, год закладки & Широта & Долгота & $\mathrm{V}_{\mathrm{N}}$, мм/год & $\mathrm{V}_{\text {E, мм/год }}$ & $\begin{array}{l}\text { Вертикальная } \\
\text { скорость, мм/год }\end{array}$ \\
\hline ELTS (ск.-2000) & 53.26 & 86.23 & 0.00 & 0.00 & 0.00 \\
\hline $\begin{array}{l}\text { Западная часть сети } \\
\text { SEMI (ск.-2000) } \\
\text { USTK (ск.-2000) } \\
\text { CHIK (ск.-2000) } \\
\text { KURA (ск.-2000) } \\
\text { KAIT (ск.-2000) } \\
\text { Среднее по западной части (Вектор: 2.6) }\end{array}$ & $\begin{array}{l}51.01 \\
50.93 \\
50.64 \\
50.24 \\
50.14\end{array}$ & $\begin{array}{l}85.62 \\
84.76 \\
86.31 \\
87.89 \\
85.43\end{array}$ & $\begin{array}{l}1.5 \pm 0.5 \\
1.4 \pm 0.5 \\
3.0 \pm 0.5 \\
2.5 \pm 0.6 \\
1.7 \pm 0.6 \\
2.0\end{array}$ & $\begin{array}{l}-2.2 \pm 0.7 \\
-2.0 \pm 0.5 \\
-1.8 \pm 0.7 \\
-1.3 \pm 0.7 \\
-0.7 \pm 0.6 \\
-1.6\end{array}$ & $\begin{array}{l}-0.6 \pm 2.6 \\
-3.3 \pm 2.4 \\
1.5 \pm 2.5 \\
2.7 \pm 2.6 \\
-3.4 \pm 2.6\end{array}$ \\
\hline $\begin{array}{l}\text { NVSK (зд.-2000) } \\
\text { KRUT (гл.-2001) } \\
\text { ANUI (ск.-2001) } \\
\text { SOLO (ск.-2001) }\end{array}$ & $\begin{array}{l}54.84 \\
53.95 \\
52.35 \\
51.70\end{array}$ & $\begin{array}{l}83.23 \\
81.20 \\
84.76 \\
84.41\end{array}$ & $\begin{array}{l}0.7 \pm 0.8 \\
-0.8 \pm 0.8 \\
0.2 \pm 0.8 \\
2.4 \pm 0.9\end{array}$ & $\begin{array}{l}-2.1 \pm 0.9 \\
1.3 \pm 0.8 \\
1.8 \pm 0.8 \\
1.00 \pm 0.9\end{array}$ & $\begin{array}{l}0.8 \pm 4.1 \\
-1.1 \pm 3.6 \\
-2.0 \pm 4.0 \\
-1.6 \pm 4.2\end{array}$ \\
\hline
\end{tabular}

П р и м е ч а н и е. Пункт ELTS расположен на равнине севернее Горного Алтая. Типы пунктов: скальный репер, заложенный за два месяца до измерений (ск.); глубинный репер, измерения после закладки (гл.) (в осадочных породах, заглубление постамента на 3-4 м); на старом здании сейсмостанции Ключи, смонтирован в июне 2000 г. (зд.); другое (массивный постамент или штанга на скальных породах) (др.); ЛЭП - пункт рядом с линией электропередачи.

$\mathrm{N}$ o t e. Station ELTS is located on the plain north of the Altai Mountains. Types of reference points: ск. - installed in the rock two months before the measurement; гл. - depth reference point in sedimentary rocks (pedestal depth 3-4 m), measurements after laying; зд. - installed in June 2000 on the old building of the Klyuchi seismic station; др. - other (massive pedestal or rod on rocks); ЛЭП - near the power line.

в северо-западной части Монголии (5-6 мм/год) и Китая (Урумчи, 10 мм/год).

Анализ поля скоростей 3D-смещений, полученного в эпоху 2000-2003 гг. проводился скриптом вычисления триангуляции Делоне из пакета GAMITGLOBK, предназначенного для получения характеристик смещений и деформаций. Использовано 22 треугольника из геодинамической сети Горного Алтая. Аномальные признаки полученных параметров в зоне будущего землетрясения, показаны на рис. 6 . Из анализа следует, что в зоне будущего землетрясения выделяются аномалии (сильные вариации) в поле скоростей на север, на восток и смена знака для вертикальных движений. Также выделяются аномалии в сдвиговой деформации и в параметрах вращения треугольников. Наличие аномальных зон в полях деформаций и смещений в области подготовки Чуйского землетрясения позволяет предположить продолжительное накопление деформаций и на- пряжений в зоне будущего землетрясения. Построение поля деформаций методом конечных элементов приведено на рис. 7 [Mazurov, 2007]. Можно отметить максимальное значение скорости в южной части сети. Также при таком способе обработки информации появляются эффекты равномерного построения вычислительной сети, заметные в «вихревых» эффектах (рис. 7).

В самом простом 2D-случае накопление и сброс смещений в зоне землетрясения описывается эллиптическим дифференциальным уравнением с частными производными второго порядка с нулевой правой частью [Turcotte, Schubert, 1982], т.е. уравнением Лапласа:

$$
\frac{\partial^{2} \omega_{z}}{\partial^{2} x}+\frac{\partial^{2} \omega_{z}}{\partial^{2} y}=0 .
$$

Рассмотрим двумерную модель циклического накопления и релаксации напряжений и деформа- 
V.Yu. Timofeev et al.: Modern movements of the crust surface in Gorny Altai...
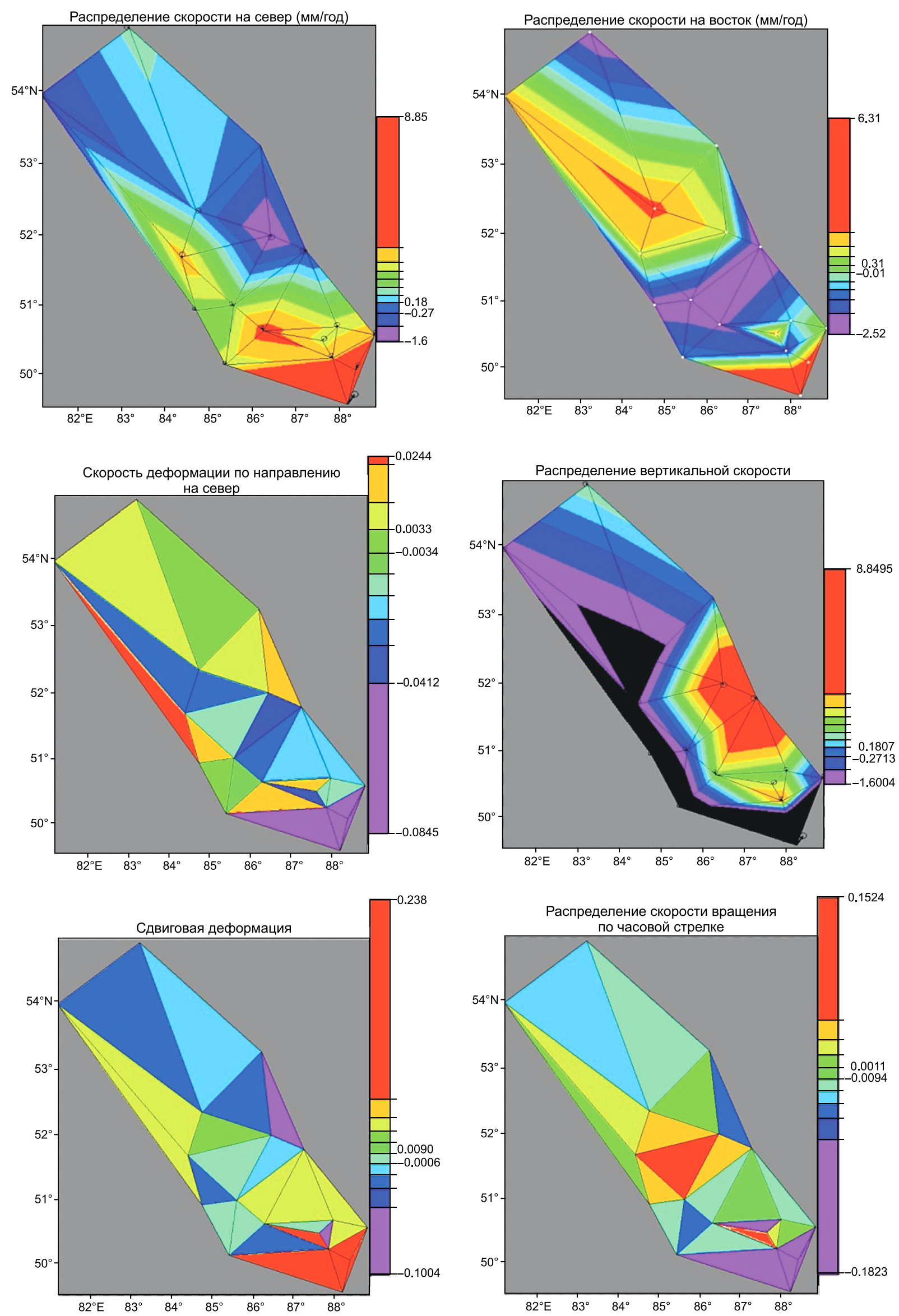

Рис. 6. Результаты обработки ежегодных данных 3D измерений за 2000-2003 гг. Приведены аномальные, т.е. отличные от нулевых значения.

Fig. 6. Processed 3D measurements of 2000-2003. Anomalous: values other than zero. 


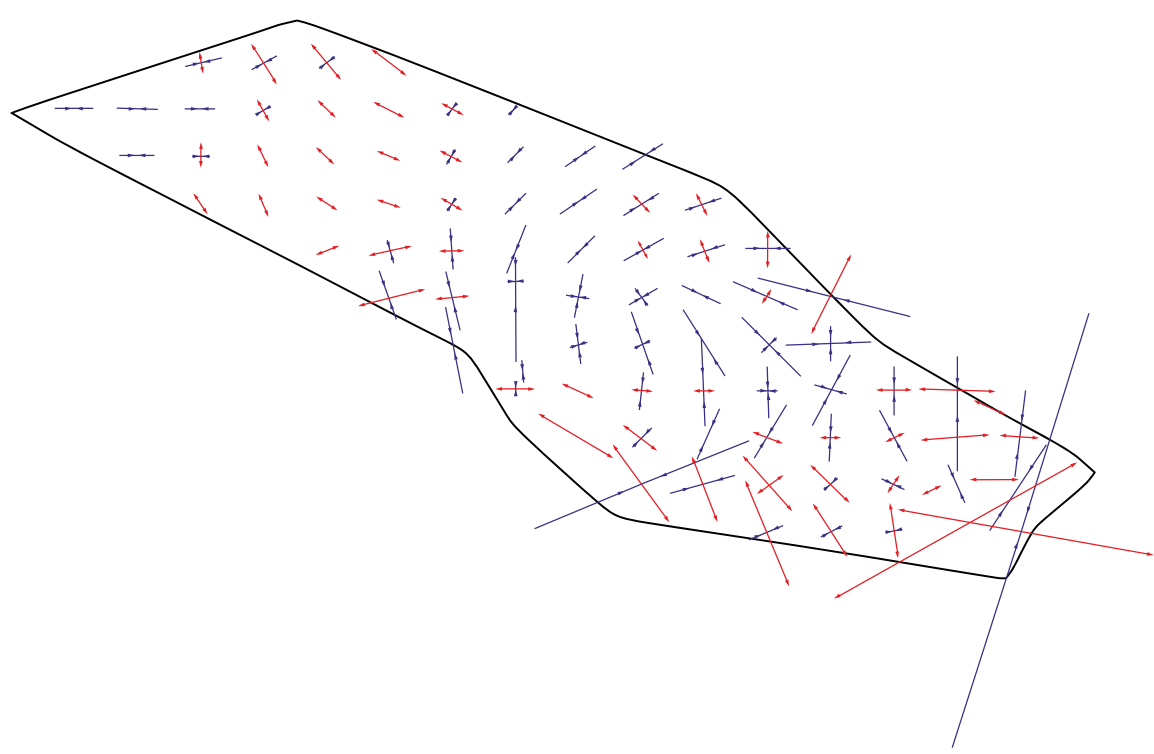

Рис. 7. Результаты определения тензора скорости деформации методом конечных элементов. Показана ориентация главных осей и величина деформации; максимальное значение (справа внизу) 2·10-7.

Fig. 7. Deformation rate tensor estimated by the finite element method. Orientations of the main deformation axes and magnitudes of deformation are shown. $2 \cdot 10^{-7}$ - maximum value (bottom right).

ций на разрыве, со смещением по простиранию [Turcotte, Schubert, 1982]. Смещение $\omega_{z}$ удовлетворяет уравнению Лапласа. Литосферные плиты толщиной $b$ находятся в состоянии однородного относительного движения, параллельного разлому. Предположим, что до глубины $a$ разлом заперт и на больших глубинах через него не передается никакого напряжения. Примем также, что подошвы плит свободны от напряжений. В результате относительного движения плит в окрестности разлома концентрируется сдвиговое напряжение и сдвиговая деформация. На поверхности смещение определяется как

$$
\omega_{z}=\operatorname{Aln}\left\{\frac{\left[\operatorname{sh}\left(\frac{\pi x}{2 b}\right)+\left(\operatorname{sh}^{2}\left(\frac{\pi x}{2 b}\right)+\sin ^{2}\left(\frac{\pi a}{2 b}\right)\right)^{1 / 2}\right]}{\sin \left(\frac{\pi a}{2 b}\right)}\right\}
$$

При малых значениях отношения $a / b$ происходит значительная концентрация напряжения у разлома. Например, при $a=10$ км и $b=150$ км происходит увеличение в 10 раз. Рассмотрим результаты расчетов и измерений накопления сдвиговой деформации в зоне будущего Чуйского землетрясения.

Теоретическое выражение для скорости поверхностной сдвиговой деформации составит:

$$
\frac{\partial e_{x z}}{\partial t}=\left(\frac{\pi}{4 b}\right)\left\{\frac{\operatorname{ch}\left(\frac{\pi x}{2 b}\right)}{\left[\operatorname{sh}^{2}\left(\frac{\pi x}{2 b}\right)+\sin ^{2}\left(\frac{\pi a}{2 b}\right)\right]^{1 / 2}}\right\} d A / d t,
$$

где $x$ - расстояние до разрыва, а параметр $d A / d t$ можно выразить через скорость смещения пункта (например, Язула (YAZU), 2.5 мм/год, табл. 1), достаточно удаленного от будущего эпицентра Чуйского землетрясения $\left(x_{r}=84\right.$ км). Для скорости имеем соотношение: $\left(\partial \omega_{z} / \partial t\right)_{r} \approx d A / d t\left(\pi x_{r} / 2 b\right)$.

Подставляя $d A / d t$, получаем:

$$
\frac{\partial e_{x z}}{\partial t}=\left[\frac{\left(\frac{\partial \omega_{z}}{\partial t}\right)_{r}}{\left(2 x_{r}\right)}\right]\left\{\frac{\operatorname{ch}\left(\frac{\pi x}{2 b}\right)}{\left[\operatorname{sh}^{2}\left(\frac{\pi x}{2 b}\right)+\sin ^{2}\left(\frac{\pi a}{2 b}\right)\right]^{1 / 2}}\right\} .
$$

Построение скорости сдвиговой деформации (4) с использованием приведенных выше параметров показано на рис. 8. Как видим, в этом случае происходит концентрация сдвиговой деформации в области будущего разрыва, что и имеем из анализа экспериментальных данных (см. рис. 6, 7).

\section{4. КОСЕЙСМИЧЕСКИЕ ЭФФЕКТЫ}

Согласно сейсмологическим и геологическим данным, Чуйское землетрясение - это правосторонний сдвиг на почти вертикальном разрыве, выходящем на поверхность, со смещением по разрыву около 2 м (табл. 2). Косейсмические смещения - это скачок положения точек, связанный с движениями по разрыву поверхности в эпицентральной зоне землетрясения.

После Чуйского землетрясения опрос по пунктам алтайской сети проводился в два этапа - весной и летом 2004 г. В пределах ошибок измерений результаты совпадают, что говорит о том, что заре- 
V.Yu. Timofeev et al.: Modern movements of the crust surface in Gorny Altai...

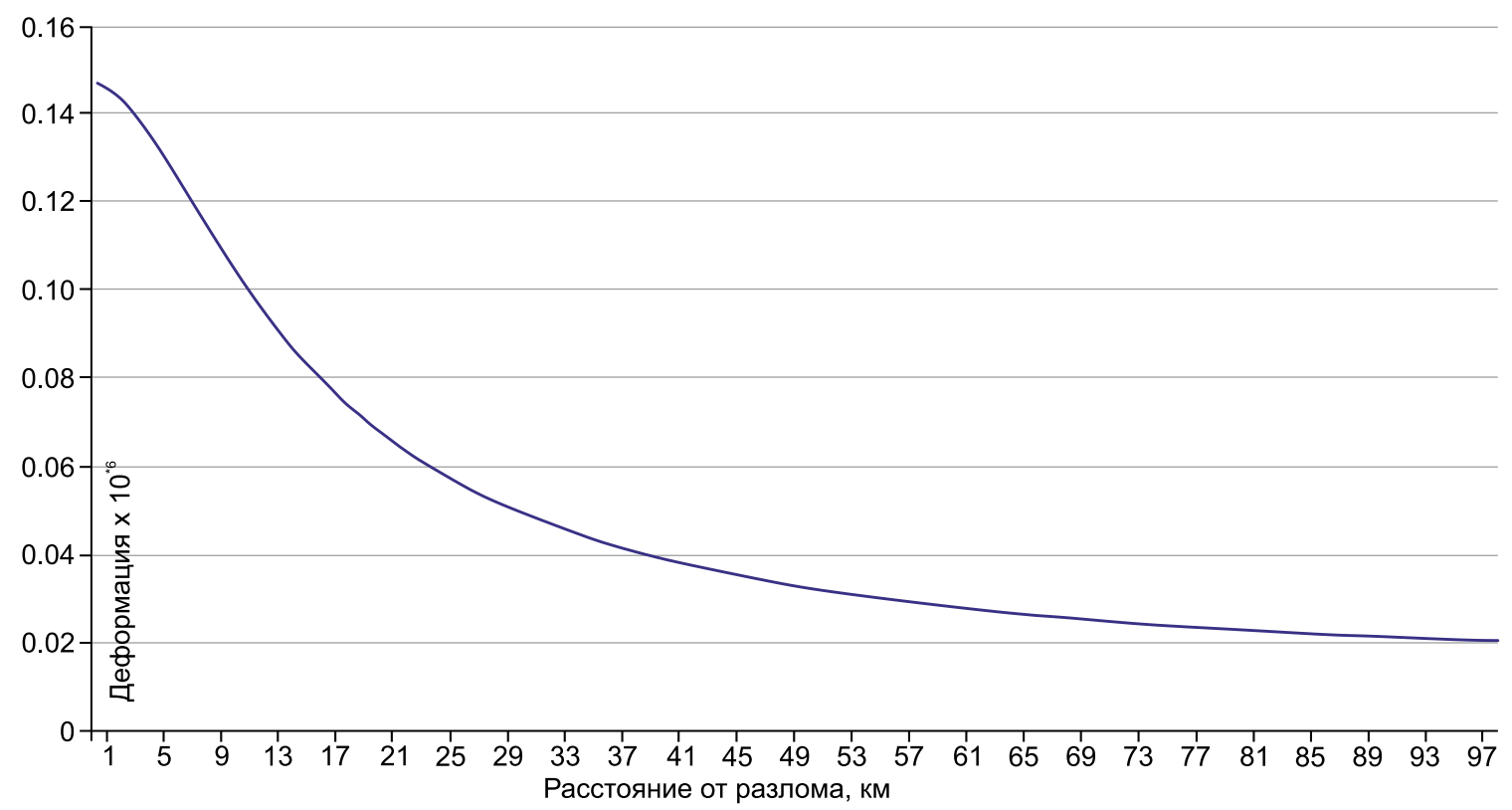

Рис. 8. Изменение скорости деформации в год в зависимости от расстояния (км) до линии будущего разрыва.

Fig. 8. Annual changes in deformation rates depending on the distance $(\mathrm{km})$ to the line of the future fault.

гистрирован эффект упругой отдачи, а величина вязкоупругого, пластического и прочих эффектов оказалась незначительной.

Полагаем, что к косейсмическим смещениям относятся результаты, которые можно описать в рамках упругой модели. В таблицах 3 и 4 приведены значения косейсмических смещений для пунктов сети. По данным за период измерений 20002017 гг. величина смещений была уточнена, результаты для ближней зоны по сравнению с анализом периода 2003-2004 гг. изменились слабо, величины скачка косейсмических смещений для дальней зоны из анализа 2000-2017 гг. значительно уменьшились.
Обнаружена зависимость величины смещения от расстояния до плоскости разрыва. Зарегистрированные смещения уменьшаются от 309 мм в 14 километрах от линии разрыва до 28 мм в 84 километрах. Вертикальные смещения на порядок меньше горизонтальных и достигают максимальных значений (от +25 до -45 мм) для трех станций (CHAG, KURA, UKOK), расположенных в ближней зоне по разные стороны от сейсмического разрыва (рис. 9). Для косейсмических смещений в зоне разрыва выделяется правостороннее смещение (см. табл. 3). Косейсмические смещения для станций сети в дальней зоне (больше 100 км) не превышают 10 мм (табл. 4). Используя ориентацию горизонтального

Т а б л и ц а 2. Определение параметров эпицентра Чуйского землетрясения (11:33:25.86, 27.09.2003 г.) по данным различных сейсмологических агентств [International Seismological Centre, 2018]

$\mathrm{T}$ a $\mathrm{b}$ l e 2. Parameters of the Chuya earthquake epicenter (11:33:25.86, 27.09.2003), according to the data from seismological agencies [International Seismological Center, 2018]

\begin{tabular}{|c|c|c|c|c|c|c|c|c|}
\hline \multicolumn{4}{|c|}{ Агентство } & Широта & Долгота & Глубина, км & Ms & Mw \\
\hline \multicolumn{4}{|c|}{ OBN (ГС РАН, Россия) } & 50.01 & 87.74 & 24 & 7.3 & \\
\hline \multicolumn{4}{|c|}{ NVS (ГС СО РАН, Россия) } & 50.00 & 88.10 & 9 & 7.5 & \\
\hline \multicolumn{4}{|c|}{ NEIC (ГС, США) } & 50.04 & 87.81 & 16 & 7.5 & 7.3 \\
\hline \multicolumn{4}{|c|}{ СМТ (Гарвардский университет, США) } & 50.02 & 87.86 & 15.0 & & 7.3 \\
\hline \multicolumn{4}{|c|}{ EIC (Япония) } & 49.98 & 87.90 & 18.4 & 7.3 & 7.2 \\
\hline \multicolumn{4}{|c|}{ USGS (США) } & 49.999 & 87.856 & 10 & 7.5 & 7.3 \\
\hline \multicolumn{9}{|c|}{ Нодальные плоскости } \\
\hline & Strike & Dip & Slip & & & & & \\
\hline NP1 & 38 & 70 & -5 & \multicolumn{5}{|c|}{ Разрыв выходит на поверхность, закартировано относительное } \\
\hline NP2 & 130 & 85 & -160 & \multicolumn{5}{|c|}{ смещение по разрыву 2 м } \\
\hline
\end{tabular}


Т а б л и ц а 3. Косейсмические смещения в эпицентральной зоне Чуйского землетрясения для пунктов к северо-востоку от линии сейсмического разрыва

$\mathrm{T}$ a b l e 3. Co-seismic displacements in the epicentral zone of the Chuya earthquake for the stations located northeast of the seismic fault line

\begin{tabular}{llllllll}
\hline Код пункта & Долгота & Широта & Высота, м & $\mathrm{V}_{\mathrm{N}}$ мм/год & $\mathrm{V}_{\mathrm{E}, \text { мм/год }}$ & Расстояние, км & Вектор, мм/год \\
\hline YAZU & 88.85 & 50.58 & 1544 & $-27.4 \pm 1.6$ & $+5.8 \pm 1.7$ & 84 & 28 \\
BALY & 88.00 & 50.70 & 1259 & $-84.0 \pm 2.1$ & $+5.5 \pm 2.8$ & 61 & 84 \\
ULAG & 87.65 & 50.50 & 2036 & $-120.4 \pm 2.5$ & $+15.6 \pm 3.1$ & 28 & 121 \\
CHAG & 88.41 & 50.06 & 1712 & $-107.7 \pm 1.9$ & $+190.4 \pm 2.1$ & 19 & 219 \\
KURA & 87.89 & 50.24 & 1492 & $-295.1 \pm 1.8$ & $+175.3 \pm 2.1$ & 14 & 309 \\
\hline
\end{tabular}

вектора смещений для пунктов CHAG (рис. 10) и KURA, максимально близких к эпицентру, можно вычислить положение плоскости разрыва. Согласно предположению, что смещение параллельно положению разрыва, его ориентация по нашим определениям оказывается $138^{\circ} \mathrm{N} \pm 15^{\circ}$.

По эффектам первого порядка, отражающим правосторонний сдвиг, можно предложить для интерпретации смещений модель упругой отдачи на вертикальном разрыве. Эффекты, на порядок меньшие (десятки миллиметров) как для горизонтальных, так и для вертикальных смещений, отражают осложняющие эффекты второго порядка (кривизну линии разрыва и наличие на отдельных участках надвиговой компоненты, известное из анализа афтершоков). Согласно дислокационной теории землетрясений, в эпицентральной зоне происходит быстрое относительное перемещение противоположных сторон разрыва. Если известна величина перемещения на поверхности разлома, то можно вычислить изменение напряжений, деформаций и смещений в каждой точке среды. В случае двумерной модели, т.е. в предположении, что в одном измерении поверхность разрыва бесконечна, можно построить несколько решений.

Для модели винтовой дислокации для разрыва, выходящего на поверхность [Stacey, 1969], имеем смещения на поверхности:

$$
\Delta \omega_{x}=\left(\frac{\Delta \omega}{2}\right) \cdot\left[1-\left(\frac{2}{\pi}\right) \cdot \operatorname{arctg}\left(\frac{x}{a}\right)\right],
$$

где $x$ - расстояние от разрыва, $a$ - глубина, $\Delta \omega-$ смещение на разрыве.

Для интерпретации горизонтальных смещений в рамках механизма упругой отдачи применим рассмотренную в работе [Turcotte, Schubert, 1982] идеализированную модель смещения по простиранию в окрестности вертикального сейсмогенного разрыва, нижняя кромка которого находится на глубине $а$. Сопровождающее землетрясение смещение

Т а б л и ц а 4. Скачок смещений (2003-2004 гг.) для пунктов Алтае-Саянской сети

T a b l e 4. Displacement jump (2003-2004) for the stations of the Altai-Sayan network

\begin{tabular}{llllll}
\hline Код пункта & Широта & Долгота & $\mathrm{V}_{\mathrm{N}, \mathrm{Mм} / \text { год }}$ & $\mathrm{V}_{\mathrm{E}, \mathrm{Mм} / \text { год }}$ & Вертикальная скорость, мм/год \\
\hline NVSK & 54.84 & 83.23 & 0.00 & 0.00 & 0.00 \\
YAZU & 50.58 & 88.85 & $-27.4 \pm 1.6$ & $+5.8 \pm 1.7$ & $+3.4 \pm 2.3$ \\
CHAG & 50.068 & 88.417 & $-107.7 \pm 1.9$ & $+190.4 \pm 2.1$ & $-45.7 \pm 2.0$ \\
BALY & 50.70 & 88.00 & $-84.0 \pm 2.1$ & $+5.5 \pm 2.8$ & $+10.1 \pm 3.8$ \\
KURA & 50.24 & 87.89 & $-295.1 \pm 1.8$ & $+175.3 \pm 2.1$ & $+25.3 \pm 2.4$ \\
ULAG & 50.50 & 87.65 & $-120.4 \pm 2.5$ & $+15.6 \pm 3.1$ & $+2.2 \pm 1.4$ \\
ARTB & 51.79 & 87.28 & $-10.2 \pm 2.1$ & $-0.3 \pm 2.4$ & $+0.0 \pm 3.4$ \\
TUNZ & 52.01 & 86.47 & $+0.3 \pm 2.1$ & $-0.6 \pm 2.3$ & $+0.4 \pm 2.8$ \\
CHIK & 50.64 & 86.31 & $-4.8 \pm 1.9$ & $-4.8 \pm 2.5$ & $+4.0 \pm 2.6$ \\
ELTS & 53.26 & 86.23 & $-3.0 \pm 1.9$ & $-0.1 \pm 2.3$ & $-0.0 \pm 1.5$ \\
SEMI & 51.01 & 85.62 & $-3.0 \pm 1.7$ & $-3.2 \pm 1.9$ & $+4.0 \pm 2.8$ \\
ANUI & 52.35 & 84.76 & $-4.0 \pm 1.8$ & $+1.8 \pm 0.8$ & $+3.0 \pm 2.9$ \\
SOLO & 51.70 & 84.41 & $-2.4 \pm 2.1$ & $-0.5 \pm 2.2$ & $+2.3 \pm 1.5$ \\
& & & & & $+19.6 \pm 6.9$ \\
UKOK & 49.56 & 88.23 & $+272.7 \pm 2.1$ & $-33.9 \pm 2.6$ & $+4.7 \pm 5.0$ \\
KAIT & 50.14 & 85.43 & $-1.6 \pm 1.7$ & $-2.75 \pm 2.0$ & $+4.6 \pm 6.7$ \\
USTK & 50.93 & 84.76 & $-0.8 \pm 1.5$ & $-1.9 \pm 1.4$ & $+5.8 \pm 6.4$ \\
KRUT & 53.95 & 81.20 & $+1.3 \pm 1.7$ & $-1.0 \pm 1.5$ & \\
\hline
\end{tabular}


V.Yu. Timofeev et al.: Modern movements of the crust surface in Gorny Altai...

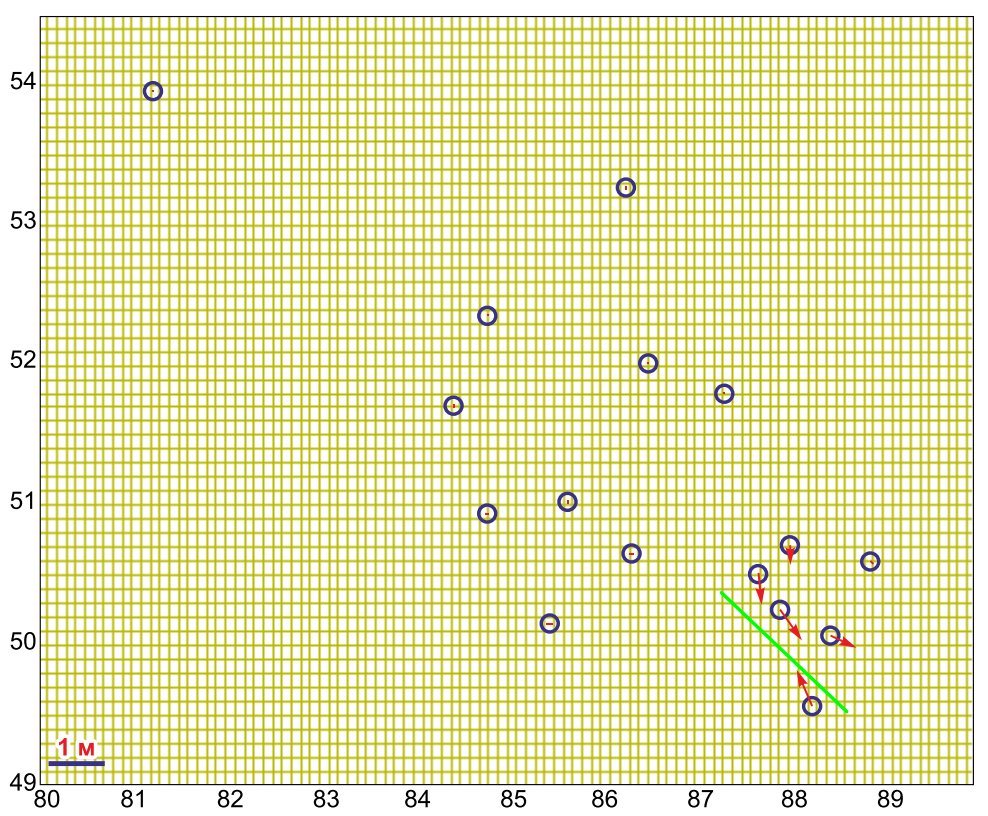

Рис. 9. Положение пунктов GPS-наблюдений Алтае-Саянской геодинамической сети (см. рис. 1) и величина косейсмических смещений с ошибкой (табл. 3, 4) при Чуйском землетрясении 27.09.2003 г. Показана линия сейсмического разрыва (зеленая линия), относительное смещение по разрыву 2 м. Скорости вне эпицентральной зоны не превышают ошибку (показана кружком).

Fig. 9. Locations of the GPS measurement stations of the Altai-Sayan geodynamic network (see Fig. 1), and the coseismic displacements with an error (see Tables 3 and 4) in case of the 27.09.2003 Chuya earthquake. Green line - seismic fault; relative displacement along the fault is $2.0 \mathrm{~m}$. The displacement rates outside the epicenter zone do not exceed the error (circle).
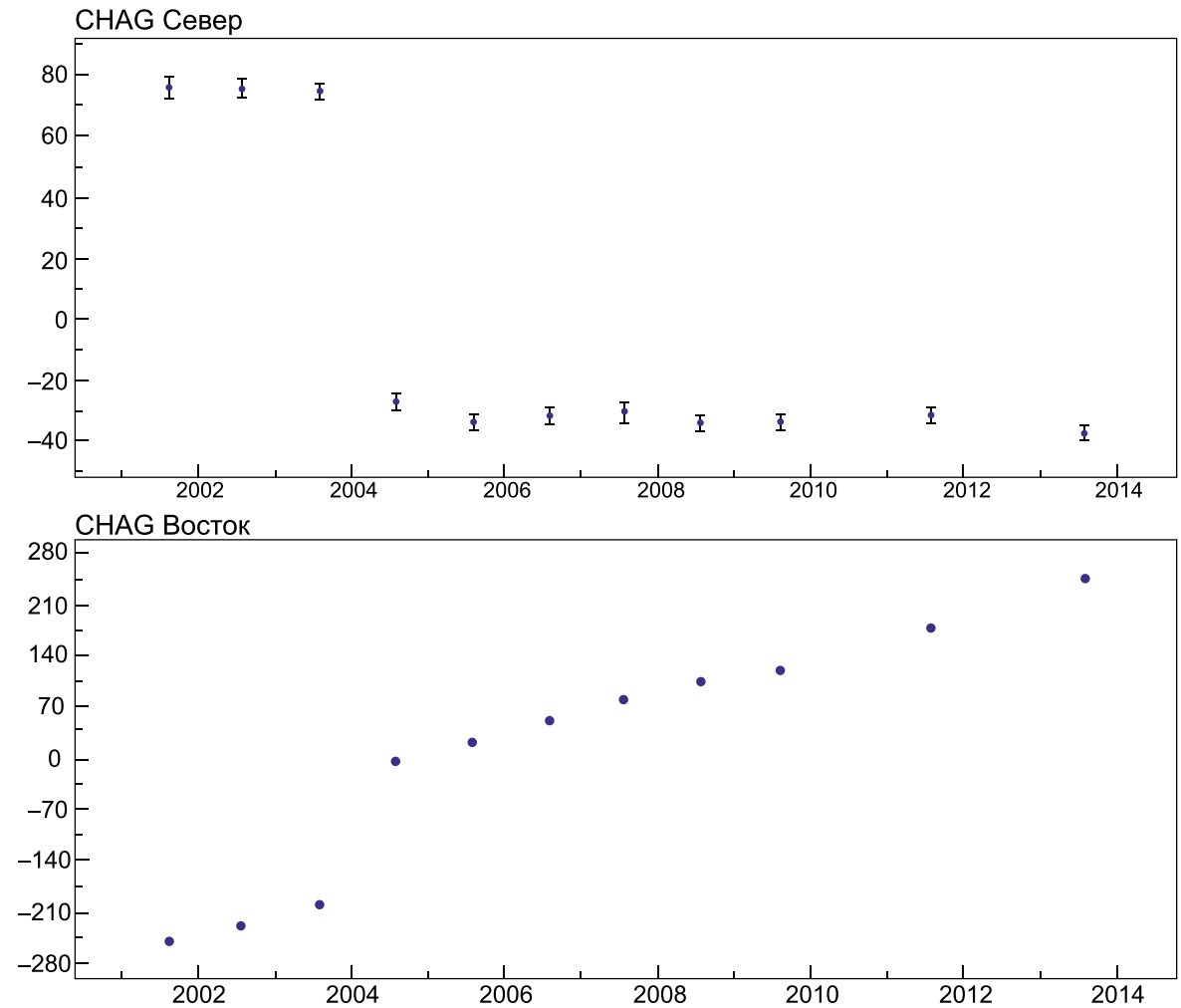

Рис. 10. Горизонтальные смещения для пункта CHAG за период 2001-2013 гг. в геоцентрической системе координат в миллиметрах. Сверху вниз: смещение на юг (-), на восток (+). Косейсмический скачок на ЮВ отмечен в эпоху 2003-2004 гг.

Fig. 10. Horizontal displacements (mm) for the CHAG station in 2001-2013 in the geocentric coordinate system. Top to bottom: southward (-) and eastward (+) displacements. Coseismic jump to SE took place in 2003-2004. 


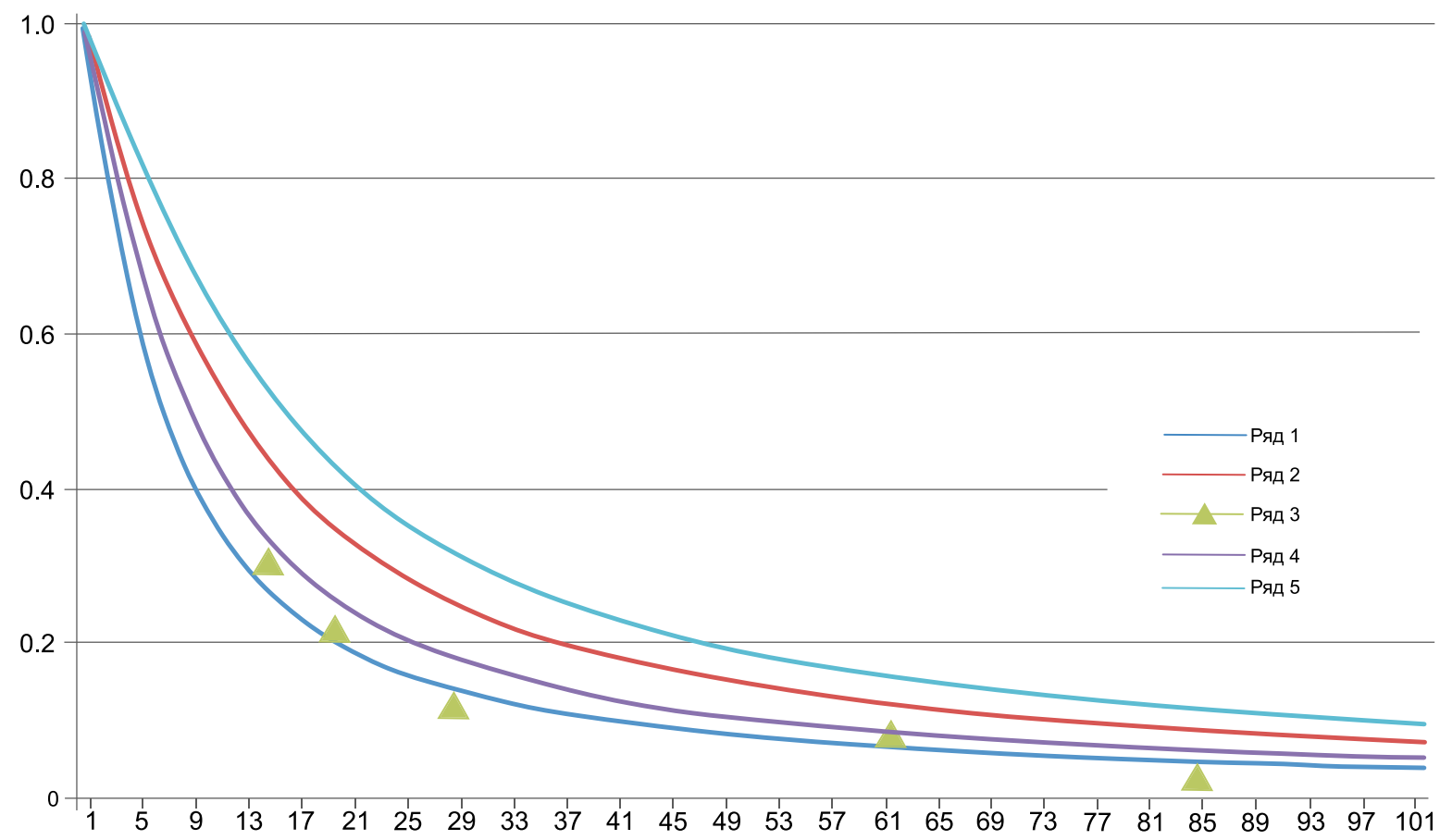

Рис. 11. Затухание смещений с расстоянием (до 100 км) от разрыва (относительное смещение по разрыву 2 м, глубина разрыва 8 и 15 км). Расчет выполнен по двум моделям (соотношения (5) - Ряд 1 и Ряд 2 и (6) - Ряд 4 и Ряд 5). Экспериментальные данные (треугольники - Ряд 3) представлены по табл. 3; вертикальная шкала в м, горизонтальная в км.

Fig. 11. Attenuation of displacements with a distance (up to $100 \mathrm{~km}$ ) from the rupture (relative displacement along the fault is $2 \mathrm{~m}$; the fault depth is $8 \mathrm{~km}$ and $15 \mathrm{~km}$ ). Two models are used for calculations: ratio (5) - Row 1 and Row 2, and ratio (6) Row 4 and Row 5. The experimental data (triangles - Row 3) are given in Table 3. Vertical scale (m). Horizontal scale (km).

поверхности в функции расстояния от разрыва можно записать как

$$
\begin{aligned}
& \Delta \omega(x) \equiv \omega(x)-\omega_{0}(x)= \\
& =\left(\frac{\Delta \omega_{0}}{2}\right)\left[\left(1+\frac{x^{2}}{a^{2}}\right)^{1 / 2}-\left|\frac{x}{a}\right|\right] \operatorname{sgn} x
\end{aligned}
$$

где $\Delta \omega_{0}=2 a \sigma_{x y}^{0} / \mu$ - смещение на разрыве $(\sigma-$ напряжение, $\mu$ - модуль сдвига).

Используем полученные соотношения для определения параметров Чуйского землетрясения (см. табл. 3). Распределение смещений (1 м на одной стороне сейсмического разрыва) с расстоянием по моделям показано на рис. 11. Как следует из приведенных графиков в рамках двумерных моделей, глубина разрыва составит 8-10 км, что соответствует верхним оценкам, полученным по сейсмологическим данным (см. табл. 2).

Расчет величин косейсмической деформации Горного Алтая проведен скриптом вычисления триангуляции Делоне из пакета GAMIT-GLOBK. Bceго использовано 22 треугольника (табл. 4), при этом несколько треугольников по краям области измерений являлись «вырожденными» и результаты, полученные в данном случае, неточны (рис. 12).
Второй вариант - это построения по данным, полученным северо-восточнее нодальной плоскости при ее продолжении через район исследований на север (табл. 4, верхний блок пунктов). В этом случае использовано 14 треугольников (рис. 13) и расчет деформации в эпицентральной области исключает сейсмический разрыв на земной поверхности. На графиках отчетливо проявляется эпицентральная зона с разными по знакам смещениями по широте и долготе. Вектор горизонтального смещения для пункта UKOK (275 мм на CC3) показан на фоне малых смещений в дальней зоне (<10 мм) (см. рис. 9, 12).

Исходя из результатов анализа экспериментальных данных, площадная и сдвиговая деформации выделяются в южной части исследуемой территории. Наиболее наглядно они показаны на рис. 12 для северо-восточной части, расположенной к северу от линии сейсмического разрыва. Сравним полученные результаты для деформации с результатами моделирования в рамках упругой 3D-модели. Полный набор замкнутых аналитических выражений для поверхностных смещений, напряжений и наклонов, вызванных различными видами разломов на полупространстве при точечном и 
V.Yu. Timofeev et al.: Modern movements of the crust surface in Gorny Altai...
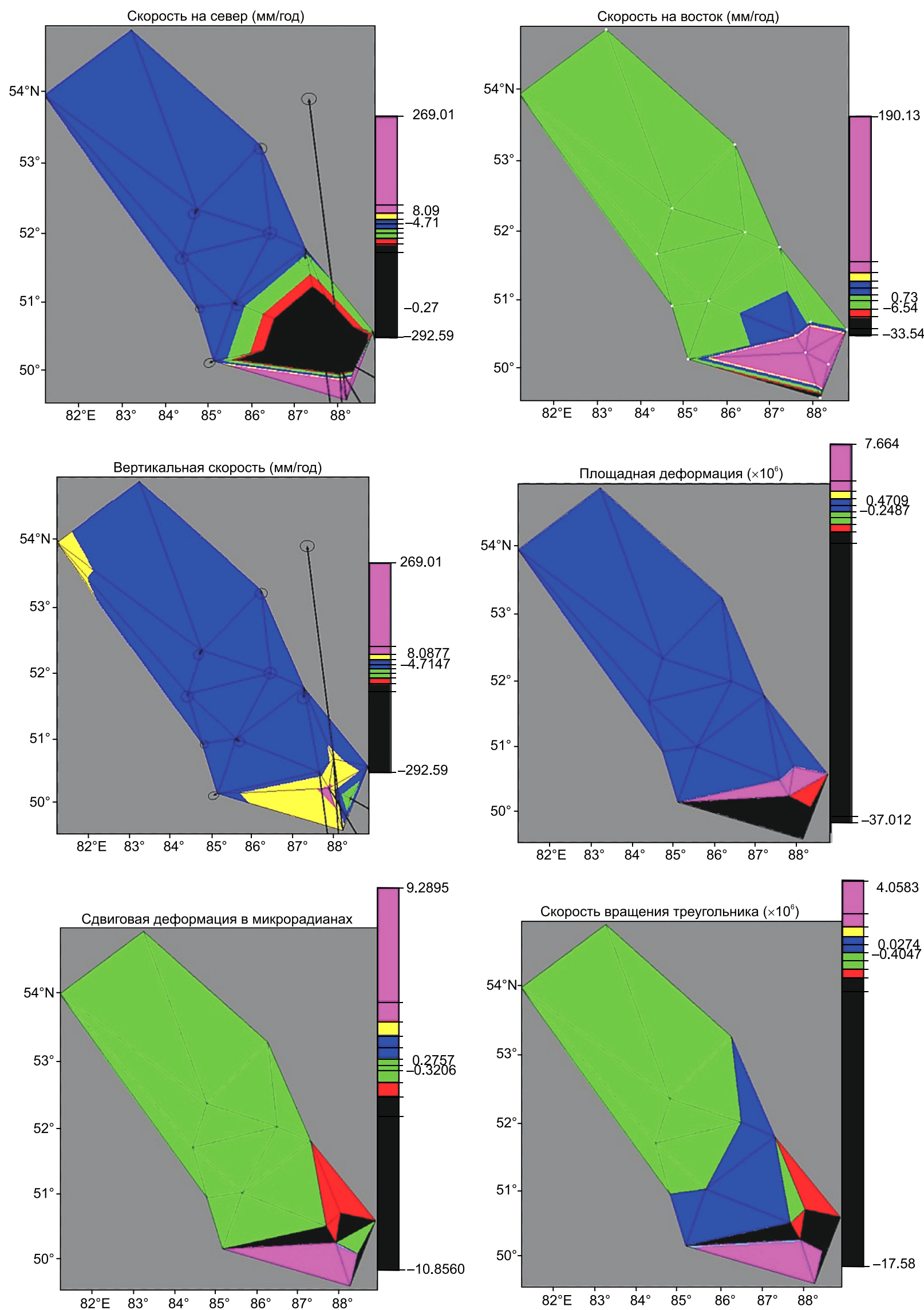

Рис. 12. Решение по 22 треугольникам для косейсмических смещений при Чуйском землетрясении по данным, приведенным в табл. 4.

Fig. 12. Solutions of 22 triangles for co-seismic displacements in case of the Chuya earthquake from the data given in Table 4. 


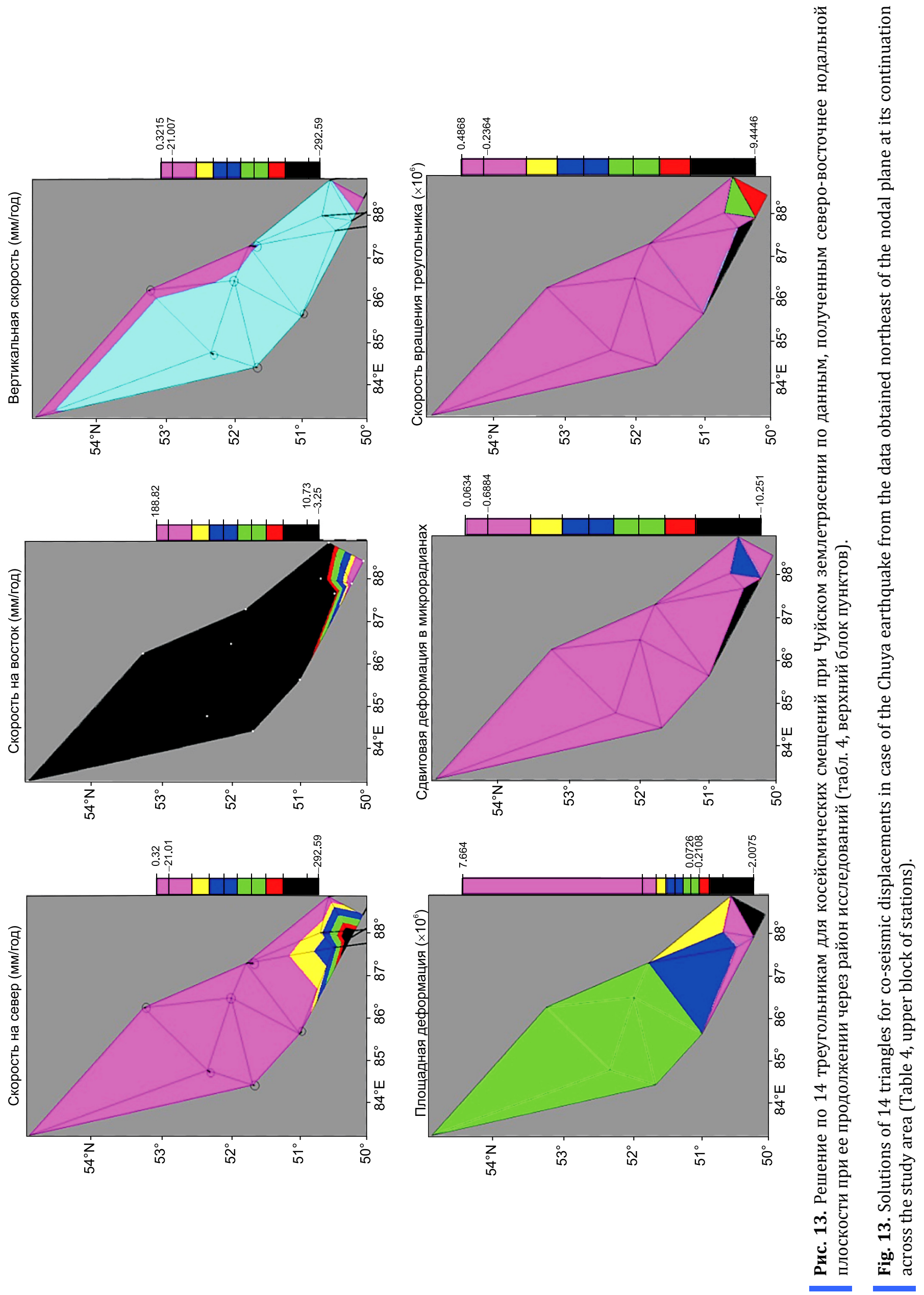


V.Yu. Timofeev et al.: Modern movements of the crust surface in Gorny Altai...

ограниченном прямоугольном источнике, проанализирован в работе [Okada, 1985]. Несмотря на значительный прогресс в теоретических вычислениях полей, анализ реальных данных обычно базируется на достаточно простых допущениях - изотропного и однородного полупространства и для простейших видов источников. В рамках модели точечного источника оказывается, что поле смещений $u_{i}\left(x_{1}, x_{2}\right.$, $\left.x_{3}\right)$, вызванное дислокацией $\Delta u_{j}\left(\xi_{1}, \xi_{2}, \xi_{3}\right)$ на поверхности изотропной среды, описывается выражениem:

$$
\begin{aligned}
& u_{i}=\left(\frac{1}{F}\right) \iint_{\Sigma} \Delta u_{j}\left\{\lambda \delta_{i j}\left(\frac{\partial u_{i}^{n}}{\partial \xi_{n}}\right)+\mu\left[\left(\frac{\partial u_{i}^{j}}{\partial \xi_{k}}\right)+\right.\right. \\
& \left.\left.+\left(\frac{\partial u_{i}^{k}}{\partial \xi_{j}}\right)\right]\right\} v_{k} d \Sigma
\end{aligned}
$$

где $\delta_{k j}$ - символ Кронекера, $\lambda$ и $\mu$ - константы Ламе, $v_{k}$ - направление косинуса нормали к элементу поверхности $d \Sigma u_{i}^{j}$ - i-я компонента смещения в точке $\left(x_{1}, x_{2}, x_{3}\right)$, обусловленная силой $F$ в точке $\left(\xi_{1}, \xi_{2}, \xi_{3}\right)$ в $j$-ом направлении, для однородного полупространства.

Для расчета полей смещений и деформаций земной поверхности исходными параметрами модельного разлома являются его геометрические размеры, положение в пространстве, величина максимального смещения в плоскости разлома и значения упругих параметров среды. При 3D моделировании использовалась модель ограниченного вертикального разрыва (программа Coulomb 3 [Toda et al., 2011]). Сравнение результатов моделирования смещений с данными эксперимента показывает хорошее соответствие (рис. 14).

\section{5. ПОСТСЕЙСМИЧЕСКИЙ И МЕЖСЕЙСМИЧЕСКИЙ ЭТАПЫ}

В результате многолетних измерений GPSметодом для эпохи 2004-2014 гг. получена картина распределения скоростей постсейсмических смещений в эпицентральной зоне Чуйского землетрясения 27.09.2003 г. (M=7.3). Постсейсмические эффекты в отличие от косейсмических рассматриваются в рамках вязкоупругих моделей, здесь появляется время, т.е. анализируется скорость смещений. Скорости на разных пунктах определялись в результате измерений на разных временных периодах от 2004-2007 гг. (Язула) до 2004-2013 гг. (Чаган-Узун). Постсейсмические движения здесь повторяют правостороннее смещение в эпицентральной зоне. В табл. 5 представлены значения скоростей на различных расстояниях от сейсмического разрыва (среднее значение вектора 2.0 мм/год, среднее для вектора в направлении, па- раллельном ориентации сейсмического разрыва, 1.9 мм/год) (рис. 15). По данным сейсмологов [Leskova, Emanov, 2013] для зоны Чуйского землетрясения известна глубина распределения афтершоков (до 30 км) и линейная протяженность области афтершоков (до 130 км).

По геофизическим данным определена глубина границы Мохоровичича (50-55 км), а, например, для Монголии в работе [Calais et al., 2002b] при моделировании принята мощность упругой коры в 20 км, а вязкоупругой нижней ее части в 25 км. Известно, что для постсейсмического процесса обычно рассматриваются несколько механизмов: асейсмическое скольжение в плоскости разрыва с учетом нижней коры [Brown et al., 1977], эффект нарушения равновесия порового давления [Peltzer et al., 1998] и вязкая релаксация в нижней коре [Pollitz, 2003]. Остановимся на вязкой релаксации и рассмотрим двухслойную модель. Она включает упругий слой толщиной $\mathrm{H}$, лежащий на вязкоупругом полупространстве [Segall, 2002], при этом субвертикальный сейсмический разрыв простирается по оси $Z$ до глубины $Z=\mathrm{D}$. В этой модели, помимо затухания, учитывается и пространственное распределение скорости (табл. 5, последний столбец). Пусть в момент времени $t=0$ происходит подвижка на разрыве, от поверхности до глубины $\mathrm{D} \leq \mathrm{H}$. Скорость на земной поверхности как функция положения по линии, перпендикулярной разрыву (по оси $x$ ), и времени $t$ записывается как

$$
v(x, t)=\left(\frac{\Delta u}{\pi} \cdot \tau_{R}\right) \cdot \exp \left(-\frac{t}{\tau_{R}}\right) F_{1}(x, \mathrm{D}, \mathrm{H}) .
$$

В соотношении для скорости (8) временная зависимость связана с безразмерным параметром $t / \tau_{M}$ и временем релаксации $\tau_{M}$ (рис. 16).

Для тела Максвелла известно соотношение для времени релаксации $\tau_{M}=2 \eta / \mu$, где $\eta$ - вязкость и $\mu-$ модуль сдвига. Пространственная зависимость $F_{1}(x$, D, H) является функцией (8): расстояния по линии, перпендикулярной разрыву (по оси $x$ ), глубины разлома D и толщины упругого слоя H (рис. 17).

$$
F_{1}(x, \mathrm{D}, \mathrm{H})=\tan ^{-1}\left\{2 x \cdot \frac{D}{\left[x^{2}+(2 \mathrm{H})^{2}-\mathrm{D}^{2}\right]}\right\}
$$

Из экспериментальных данных при времени релаксации $\tau_{M} \geq 100$, т.е. при $\tau_{M}$ от 100 до 300 лет и модуле сдвига нижней коры $\mu$ от 41 до 73 ГПа приходим к значениям вязкости нижнего слоя от $6 \cdot 10^{19}$ до $3 \cdot 10^{20}$ Па·с. Подобные оценки получены для процессов, связанных с землетрясением на Аляске (03.11.2002 г., M=7.9) [Freed et al., 2006]. Авторы считают, что вязкость экспоненциально изменяется в коре от $10^{21}$ Па·с (20 км) до $10^{19}$ Па.с (50 км). Для землетрясения в Монголии 1905 г. 

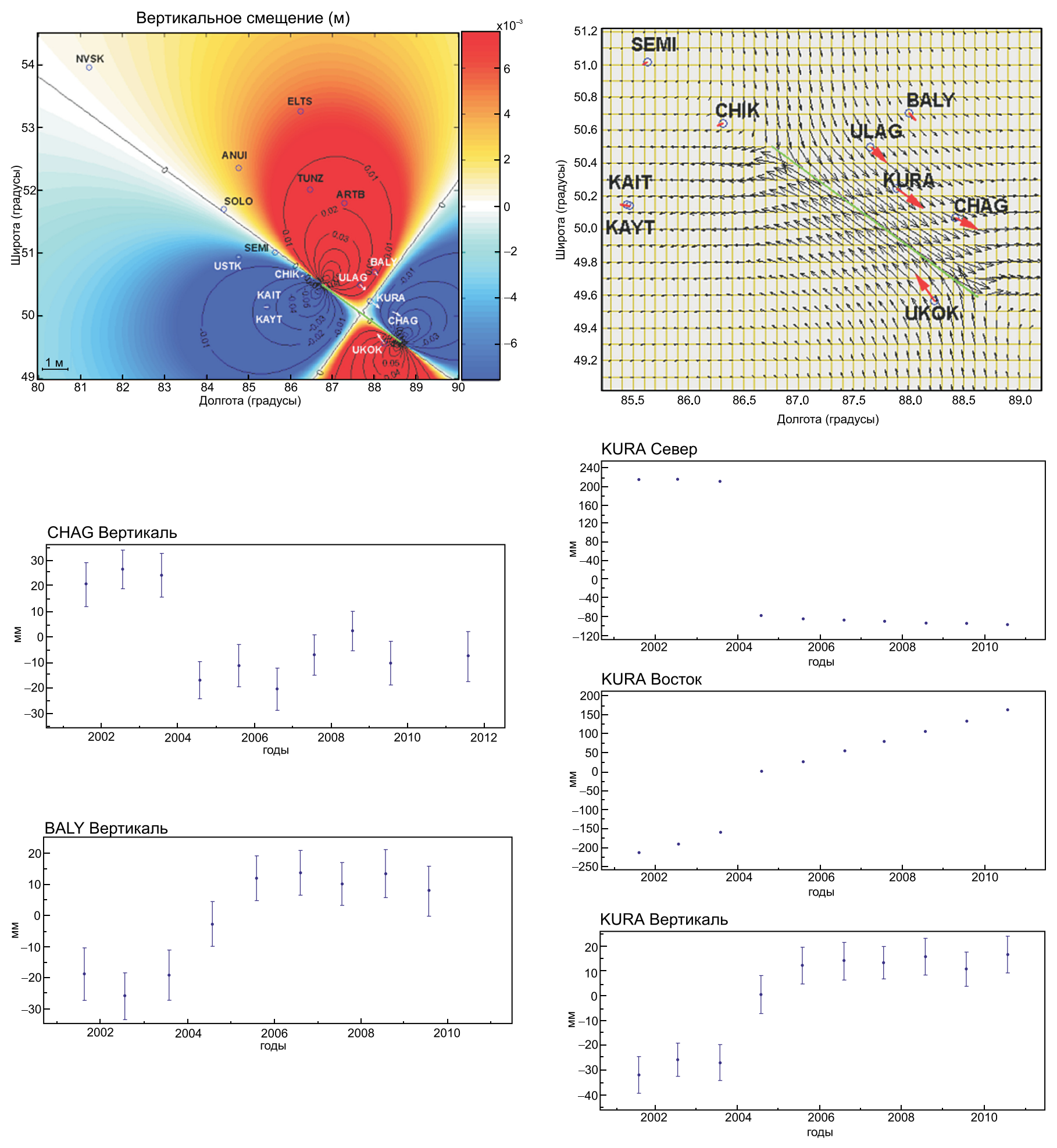

Рис. 14. Моделирование смещений и эксперимент. Сверху - модели вертикальных смещений по сети и горизонтальных смещений в эпицентральной зоне, зеленая линия - сейсмический разрыв (относительное смещение вдоль разрыва 2 м). Ниже слева - вертикальные косейсмические смещения на пунктах CHAG - Чаган-Узун (вниз на 30 мм) и BALY - Балыкуюль (20 мм вверх), справа внизу - смещения на пункте KURA - Курай на юг, на восток и вверх в миллиметрах. Скачок на периоде 2003-2004 гг.

Fig. 14. Displacement models, and the experiment. Top - models of vertical displacements along the network and horizontal displacements in the epicenter area, green line - seismic fault (relative displacement along the fault is $2 \mathrm{~m}$ ). Below left - vertical co-seismic displacements at stations CHAG - Chagan-Uzun (30 mm down) and BALY - Balykuyul (20 mm up). Bottom right - displacements at station KURA - Kurai to the south, to the east and upward (mm). Displacement jump in 2003-2004. 
V.Yu. Timofeev et al.: Modern movements of the crust surface in Gorny Altai...

Т а б л и ц а 5. Скорости постсейсмических горизонтальных смещений на различных расстояниях от сейсмического разрыва (L)

$\mathrm{T}$ a b l e 5. Post-seismic horizontal displacement rates at various distances from the seismic fault (L)

\begin{tabular}{llllllll}
\hline Код марки & Долгота & Широта & $\mathrm{H}, \mathrm{M}$ & $\mathrm{V}$ Е, мм/год & $\mathrm{V}_{\mathrm{N}, \text { мм/год }}$ & L, км & Вектор \|, мм/год \\
\hline YAZU & 88.851 & 50.586 & 1544 & $+2.15 \pm 0.58$ & $+0.50 \pm 0.62$ & 84 & 1.1 \\
BALY & 88.002 & 50.703 & 1260 & $+1.60 \pm 0.30$ & $-1.41 \pm 0.30$ & 61 & 2.1 \\
ULAG & 87.654 & 50.500 & 2036 & $+2.04 \pm 0.48$ & $-1.43 \pm 0.51$ & 28 & 2.3 \\
CHAG & 88.417 & 50.068 & 1713 & $+2.05 \pm 0.26$ & $-0.57 \pm 0.29$ & 19 & 2.1 \\
KURA & 87.890 & 50.245 & 1493 & $+1.92 \pm 0.29$ & $-2.23 \pm 0.27$ & 14 & 2.8 \\
CHIB & 87.503 & 50.313 & 1122 & $+0.53 \pm 0.35$ & $-1.04 \pm 0.38$ & 5 & 1.1 \\
Среднее & & & & $+1.71 \pm 0.24$ & $-1.03 \pm 0.38$ & & $1.91 \pm 0.28$ \\
\hline
\end{tabular}

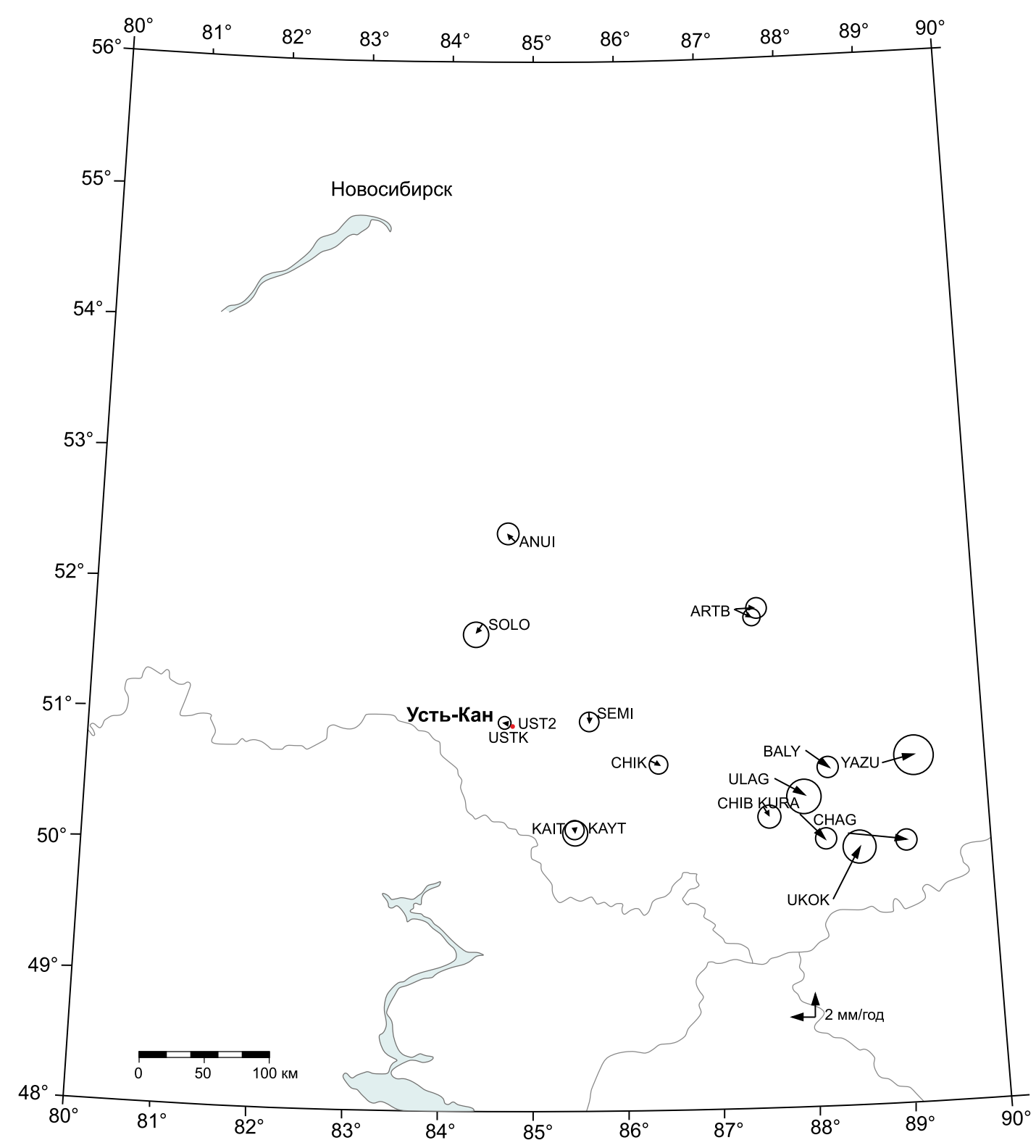

Рис. 15. Скорости относительных постсейсмических смещений для Горного Алтая (смещения относительно пункта USTK - Усть-Кан). Линии внизу - государственные границы. Период наблюдений 2004-2013 гг.

Fig. 15. Relative post-seismic displacement rates for the Gorny Altai region (displacements relative to station USTK Ust-Kan). The lines below show the state borders. Observation period 2004-2013. 


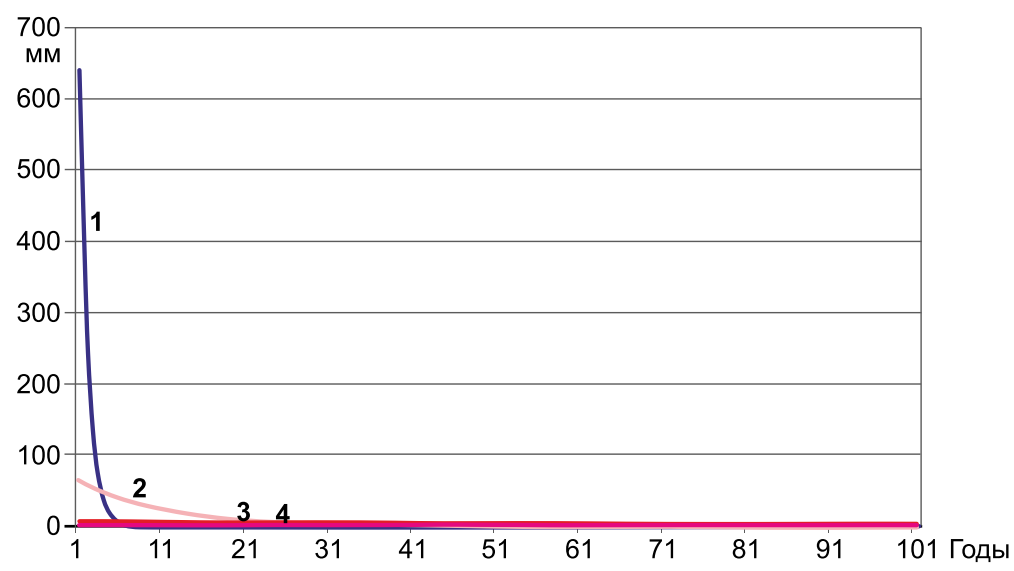

Рис. 16. Скорость постсейсмического смещения при различных параметрах, согласно соотношению (8) (часть, зависимая от времени). Зависимость соотношения $\left(\Delta \mathrm{u} / \pi \cdot \mathrm{t}_{\mathrm{R}}\right) \cdot\left(\mathrm{e}^{-\mathrm{t} / \mathrm{tR}}\right)$ от времени $(\mathrm{t})$ при разных временах релаксации: (1) - 1 год; (2) - 10 лет; (3) - 100 лет; (4) - 1000 лет. Изменение за 100 лет. Косейсмическое смещение 2000 мм, вертикальная шкала в миллиметрах.

Fig. 16. Post-seismic displacement rates for different parameters, according to ratio (8) (part dependent on time). Dependence of ratio $\left(\Delta \mathrm{u} / \pi \cdot \mathrm{t}_{\mathrm{R}}\right) \cdot\left(\mathrm{e}^{-\mathrm{t} / \mathrm{tR}}\right)$ on time $(\mathrm{t})$ for different relaxation times: (1) - 1 year; (2) - 10 years; (3) - 100 years; (4) 1000 years. Change over 100 years. Co-seismic displacement is $2000 \mathrm{~m}$. Vertical scale (mm).
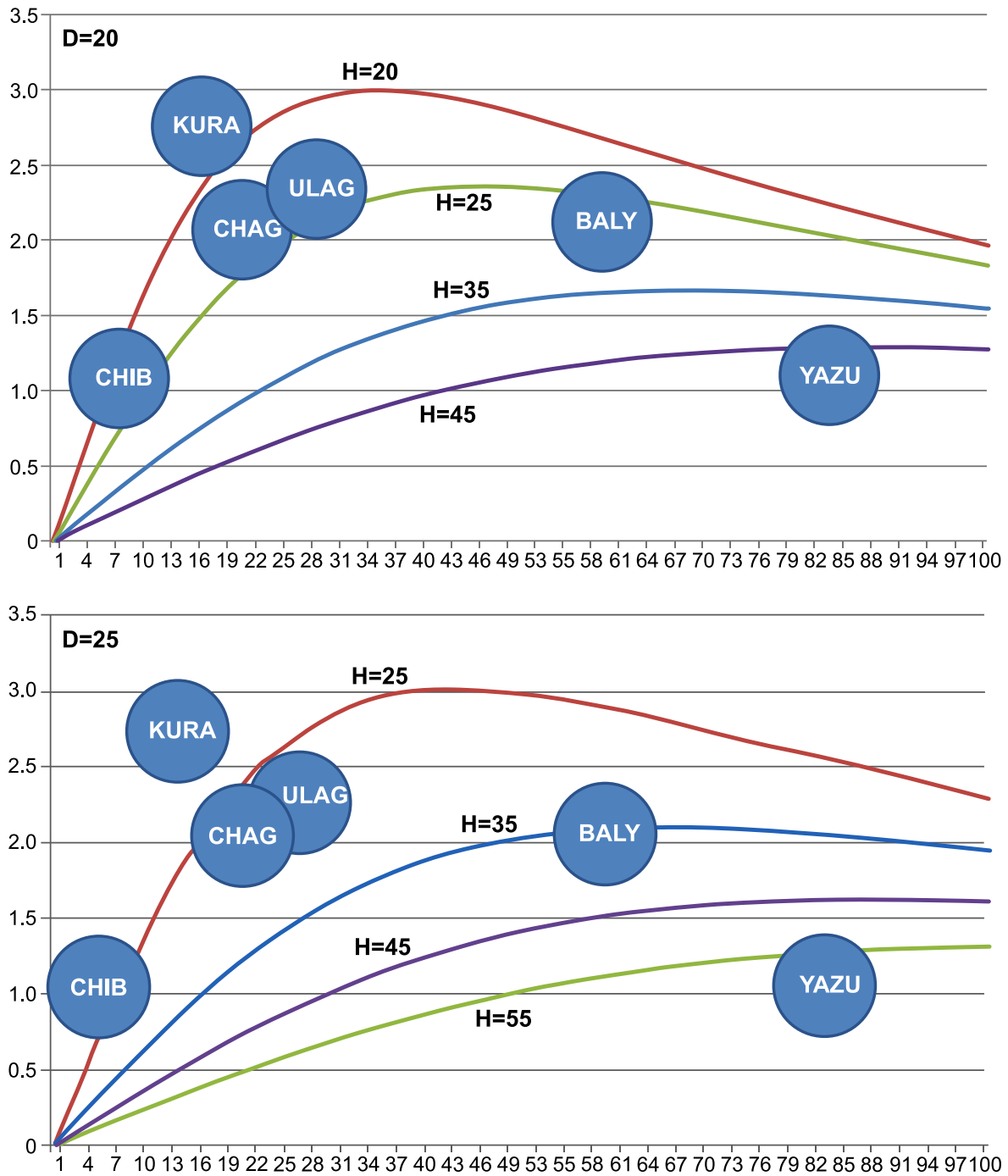

Рис. 17. Распределение скоростей горизонтальных смещений (мм/год) в направлении ортогональном разрыву (по оси X до 100 км). Теоретические кривые по соотношениям (8) и (9) рассчитаны при разной мощности упругого слоя (Н от 20 до 55 км), при времени после события $\mathrm{t}=10$ лет; при времени релаксации $\tau_{\mathrm{R}}=100$ лет, относительном смещении на разрыве $\Delta \mathrm{u}=2$ м, при глубине разрыва $\mathrm{D}=20$ и 25 км. Ошибка определения от 0.3 до 0.6 мм/год. Для верхней коры (упругий слой) оценка мощности близка к значению $\mathrm{H}=25$ км.

Fig. 17. Distribution of horizontal displacement rates $(\mathrm{mm} / \mathrm{yr})$ in the direction orthogonal to the fault (along axis X up to $100 \mathrm{~km})$. The theoretical curves from ratios (8) and (9) are calculated for different values of the elastic layer thickness $(\mathrm{H}$ from 20 to $55 \mathrm{~km}$ ). Time after the event, $\mathrm{t}=10$ years. Relaxation time, $\tau_{\mathrm{R}}=100$ years. Relative displacement along the fault, $\Delta \mathrm{u}=2 \mathrm{~m}$. Fault depth, $\mathrm{D}=20$ and $25 \mathrm{~km}$. Estimation error from 0.3 to $0.6 \mathrm{~mm} / \mathrm{yr}$. According to the estimations, the upper crust (elastic layer) thickness, $\mathrm{H}$ is approximately $25 \mathrm{~km}$. 
V.Yu. Timofeev et al.: Modern movements of the crust surface in Gorny Altai...

Т а б л и ц а 6. Смещение пунктов Горного Алтая, расположенных вне эпицентральной зоны

$\mathrm{T}$ a b l e 6. Displacements in the Gorny Altai region, according to the data from the stations located outside the epicentral zone of the Chuya earthquake

\begin{tabular}{|c|c|c|c|c|c|c|c|c|c|}
\hline \multirow[t]{2}{*}{ Код пункта } & \multirow[t]{2}{*}{ Широта } & \multirow[t]{2}{*}{ Долгота } & \multirow[t]{2}{*}{$\mathrm{H}, \mathrm{M}$} & \multicolumn{2}{|c|}{ Модель } & \multicolumn{2}{|c|}{ Эксперимент } & \multicolumn{2}{|l|}{ Разность } \\
\hline & & & & $\mathrm{V} \varphi$ & $\mathrm{V} \lambda$ & $\mathrm{V} \varphi$ & $\mathrm{V} \lambda$ & $\mathrm{V} \varphi$ & $\mathrm{V} \lambda$ \\
\hline ART2 (2005-2012) & 51.799 & 87.282 & 461 & -2.263 & 26.658 & $-0.94 \pm 0.35$ & $26.42 \pm 0.34$ & +1.32 & -0.24 \\
\hline CHIK (2001-2015) & 50.644 & 86.313 & 1249 & -1.990 & 26.837 & $-1.01 \pm 0.21$ & $25.41 \pm 0.18$ & +0.98 & -1.43 \\
\hline SEMI (2001-2014) & 51.014 & 85.626 & 1488 & -1.796 & 26.808 & $-0.87 \pm 0.16$ & $26.19 \pm 0.15$ & +0.92 & -0.62 \\
\hline USTK (2001-2017) & 50.939 & 84.769 & 1004 & -1.553 & 26.837 & $-0.88 \pm 0.08$ & $26.58 \pm 0.08$ & +0.67 & -0.26 \\
\hline UST2 (2005-2017) & 50.939 & 84.768 & & & & $-0.78 \pm 0.09$ & $27.01 \pm 0.09$ & +0.77 & +0.17 \\
\hline KAIT (2001-2017) & & & & & & & & $+1.03 \pm 0.08$ & $-0.60 \pm 0.17$ \\
\hline
\end{tabular}

П р и м е ч а н и е. Координаты пунктов, скорости, экспериментальные данные (с 2001-2005 по 2017 г.) и остаточные значения показаны относительно модели Евразии SOPAC-2008 (координаты полюса Эйлера для Евразии: $55.85^{\circ} \mathrm{N}, 262.62^{\circ} \mathrm{E}$, угловая ско-

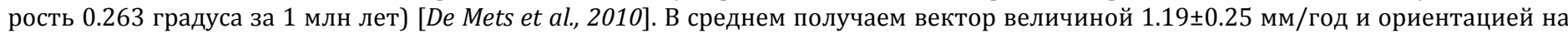
CC3 $\left(-30^{\circ} \mathrm{N}\right)$.

$\mathrm{N}$ o t e. The coordinates of the stations, displacement rates, experimental data (from 2001-2005 to 2017), and the residual values are shown relative to the SOPAC-2008 model of Eurasia (Euler pole coordinates for Eurasia: $55.85^{\circ} \mathrm{N}, 262.62^{\circ} \mathrm{E}$, angular velocity 0.263 degrees per $1 \mathrm{Ma})$ [De Mets et al., 2010]. On average: vector of $1.19 \pm 0.25 \mathrm{~mm} / \mathrm{yr}$, oriented to $\mathrm{NNW}\left(-30^{\circ} \mathrm{N}\right)$.

(M=8.4) при моделировании [Calais et al., 2002b] авторами рассматривались значения вязкости для нижней коры от $3 \cdot 10^{18}$ до $3 \cdot 10^{20}$ Па·с.

В итоге для Горного Алтая в настоящее время имеем следующую ситуацию: на юго-востоке в эпицентральной зоне Чуйского землетрясения продолжается затухание постсейсмических смещений (1-2 мм/год) (табл. 6). Рассмотрим ситуацию для региона в целом. Получение материалов ежегодных измерений за периоды более десяти лет позволяет оценить скорости смещения земной коры Горного Алтая в целом относительно Евразии. Из осложняющих факторов при определении вековых (тектонических) скоростей движений следует отметить современный сейсмический процесс. Связь со структурными элементами региона, по нашему мнению, проявилась слабо, что определяется малыми скоростями тектонических смещений на структурных границах земной коры. Ошибка определения скоростей около 0.5 мм, видимо, может служить ограничением величины скоростей в год (для разломов и границ блоков). Для пунктов сети, расположенных вне эпицентральной зоны, получены значения горизонтальных скоростей, определенных на многолетней временной базе (рис. 18, табл. 6).

Современная скорость горизонтальных тектонических движений Горного Алтая относительно северной части Евразии составляет 1.19 мм/год. Получена ориентация скорости смещений на северо-запад $\left(-30^{\circ} \mathrm{N}\right)$. Заметим, что полученная величина скорости в два раза меньше скорости на С3, полученной перед землетрясением для западной части Горного Алтая.
Для вертикальных смещений ситуация более сложная [Ardyukov et al., 2017] и требует рассмотрения комплекса реологических моделей.

\section{6. ЗАКЛЮЧЕНИЕ}

Для исследования современного состояния поля смещений земной поверхности методами космической геодезии в 2000-2004 гг. создана Алтае-Саянская геодинамическая сеть, простирающаяся от Новосибирска до монгольской границы, на территории от 49 до $55^{\circ}$ с.ш. и от 81 до $89^{\circ}$ в.д. Для анализа данных использованы программные пакеты GAMIT-GLOBK с приложениями и Coulomb 3. По peзультатам исследований с 2000 по 2017 г. получены новые оценки горизонтальных смещений земной поверхности Горного Алтая.

Анализ поля смещений и деформаций Евразии показывает, что Горный Алтай в целом находится в состоянии стесненного сжатия и является северной частью области деформирования Южной и Центральной Азии. В эпоху перед крупным землетрясением в Горном Алтае (2000-2003 гг.) выявлены аномалии (относительно плитного движения северной части Евразии) в распределении скоростей современных движений земной коры. Изменение ориентации направления горизонтальных движений выделено в зоне будущего землетрясения. При этом юго-восточная часть Горного Алтая движется на ССВ со скоростью от 11 до 2 мм/год. Такая компонента смещений проявляется также на пунктах Южной Азии, от Тибета (Лхаса) через Западный 

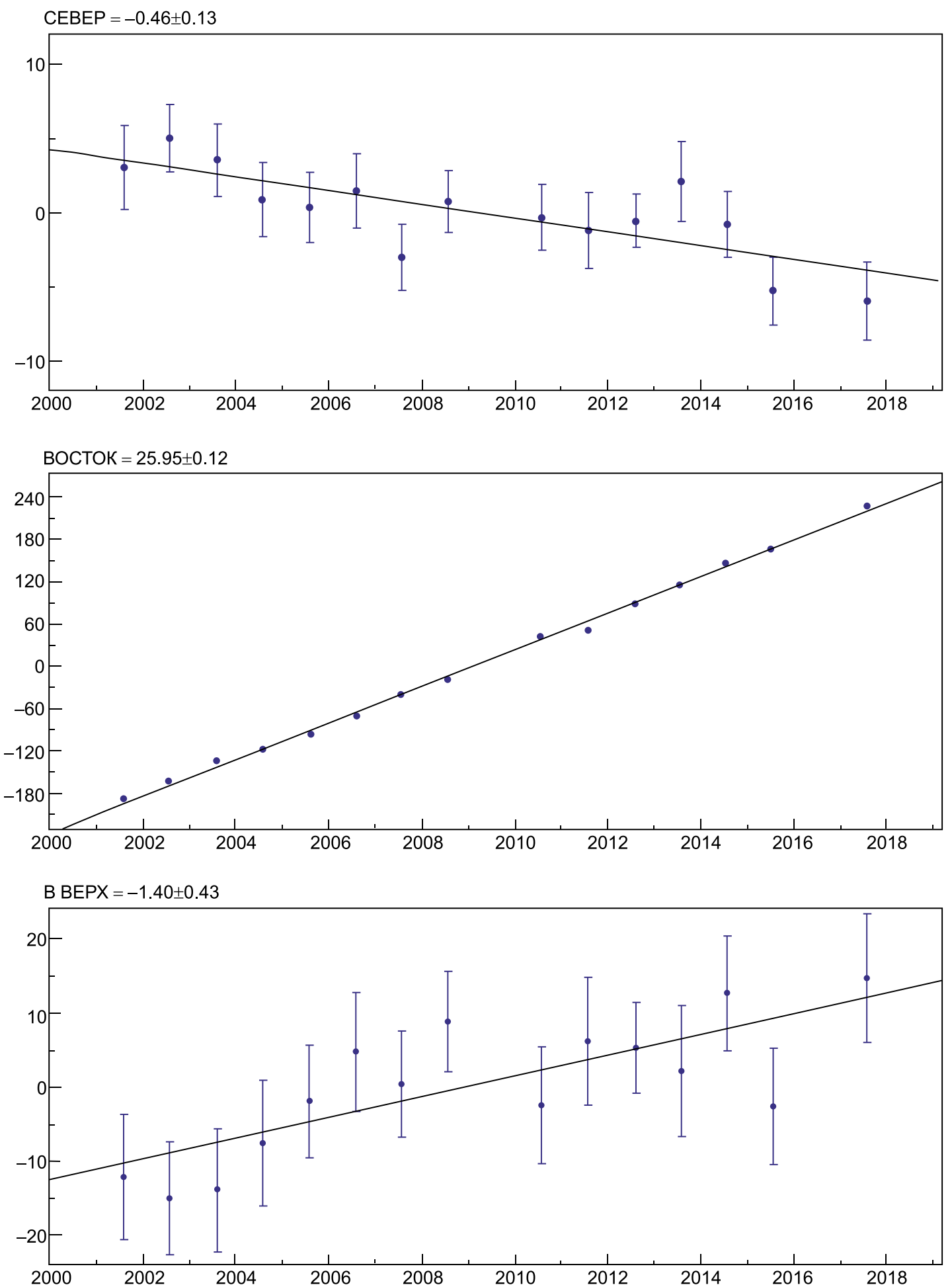

Рис. 18. Изменение пространственного положения пункта Кайтанак-скальный (KAIT) по компонентам север - юг, восток - запад, вверх - вниз за период 2001-2017 гг. в миллиметрах. Приведены значения годовой скорости, включая горизонтальное плитное смещение (наиболее значимо в этой части Евразии смещение на восток).

Fig. 18. Changes in the spatial position of station KAIT (Kaitanak-Skalny) in 2001-2017. Components: north - south, east west, up and down ( $\mathrm{mm}$ ). Annual displacement rates, including horizontal shifting of the plate (in this region of Eurasia, shifting to the east is dominant).

Китай (Урумчи) до Северо-Западной Монголии. Горизонтальная скорость в западной части Горного Алтая в среднем составляет 2.6 мм/год при ориен- тации смещений на СЗ. Одним из признаков подготовки будущего Чуйского землетрясения можно считать высокие скорости смещений и разделение 
направлений движения в зоне будущего эпицентра. Помимо аномальных скоростей, при подготовке землетрясения можно отметить повышение величины деформаций. Аномальное поведение 3D-скоростей и деформаций выделено в результате использования пакета обработки данных GAMITGLOBK и скрипта вычисления триангуляции Делоне, предназначенного для получения характеристик смещений и деформаций. Полученные признаки могут рассматриваться как элементы среднесрочного прогноза землетрясений.

Для эпохи Чуйского землетрясения получено поле косейсмических смещений, которые рассматриваются в рамках упругой модели. Для ближней эпицентральной зоны по данным шести пунктов (2003-2004 гг.) выделены горизонтальные смещения до 309 мм в 14 км от эпицентра Чуйского землетрясения. Распределения смещений после землетрясения (правосторонний сдвиг в эпицентральной части), уменьшение величины смещений с увеличением расстояния от разрыва, особенности поля скоростей до события приводят к выбору модели упругой отдачи для описания смещений в эпицентральной зоне. Измеримые смещения земной коры охватывают территорию с поперечными размерами более ста километров. Экспериментальные результаты и 2D-модельные соотношения позволили определить ориентацию разрыва $\left(138 \pm 15^{\circ}\right)$ и глубину разрыва (8-10 км) при относительном смещении по разрыву 2 м. Деформации земной коры концентрируются в эпицентральной зоне (100200 км) и достигают единиц на 10-5. 3D-моделирование показывает хорошее соответствие экспериментальным значениям смещений и сейсмологическими данными.

Распределение постсейсмических смещений (2004-2013 гг.) показывает правостороннее движение в эпицентральной области со скоростью около 2 мм/год. Эти эффекты рассматриваются в рамках упруговязкой модели. По пространственному распределению постсейсмических смещений и двухслойной модели релаксации определена мощность верхней упругой части земной коры (25 км) и значение вязкости нижнего слоя (0.63.0) $10^{20}$ Па.с.

С исключением эпицентральной области по экспериментальным данным (2000-2017 гг.) получена оценка современных вековых (тектонических) движений для Горного Алтая в целом как среднее для восьми пунктов $\left(1.19 \pm 0.25\right.$ мм/год на ССЗ $\left.\left(-30^{\circ} \mathrm{N}\right)\right)$. В этом случае рассматриваем аномальное (относительно северной части Евразии) плитное движение всего Горного Алтая. Скорость полученных межсейсмических движений оказалась более чем в два раза меньше скоростей, зарегистрированных перед Чуйским землетрясением.

\section{7. ЛИТЕРАTУPA / REFERENCES}

Ardyukov D.G., Arnautov G.P., Boyko E.V., Kalish E.N., Nazarov E.O., Nosov D.A., Sizikov I.S., Smirnov M.G., Stus Y.F., Timofeev A.V., Timofeev V.Yu., 2017. Vertical displacement and gravity change after Chuya earthquake at west part of Gorny Altay. Vestnik of the Siberian State University of Geosystems and Technologies 22 (1), 58-69 (in Russian) [Apдюков Д.Г., Арнаутов Г.П., Бойко Е.В., Калиш Е.Н., Назаров Е.О., Носов Д.А., Сизиков И.С., Смирнов М.Г., Стусь Ю.Ф., Тимофеев А.В., Тимофеев В.Ю. Вертикальные смещения и изменения силы тяжести в западной части Горного Алтая после Чуйского землетрясения 2003 года // Вестник СГУГиТ. 2017. Т. 22. № 1. С. 58-69].

Brown L.D., Reilinger R.E., Holdahl S.R., Balazs E.I., 1977. Postseismic crustal uplift near Anchorage, Alaska. Journal of Geophysical Research 82 (23), 3369-3378. https://doi.org/10.1029/JB082i023p03369.

Calais E., Dong L., Wang M., Shen Z., Vergnolle M., 2006. Continental deformation in Asia from a combined GPS solution. Geophysical Research Letters 33 (24), L24319. https://doi.org/10.1029/2006GL028433.

Calais E., Lesne O., Vergnolee M., Déverchère J., Sankov V., Lukhnev A., Miroshnitchenko A., Buddo V., Levi K., Zalutski V., Baskkuev Y., Dembelov M., Amarijargal S., Bekhtur B., Timofeev V., Duchkov A., Buslov M., Zapreeva E., Ardukov D., Arnautov G., Schelochkov G., Bragin D., Zubovich A.V., Ducarme B., Bruyminx C., Delvaux D., 2002a. GPS Measurements of active crustal deformation in Central Asia (Baikal-Mongolia-Altay). In: Proceedings of the 2-d international symposium on the geodynamics and environmental problems of high-mountain regions. IPHT-Bishkek, Bishkek, Kyrgyztan, p. 50-58.

Calais E., Vergnolle M., Déverchère J., San'kov V., Lukhnev A., Amarjargal S., 2002b. Are post-seismic effects of the M=8.4 Bolnay earthquake (1905 July 23) still influencing GPS velocities in the Mongolia-Baikal area? Geophysical Journal International 149 (1), 157-168. https://doi.org/10.1046/j.1365-246X.2002.01624.x.

DeMets C., Gordon R.G., Argus D.F., 2010. Geologically current plate motions. Geophysical Journal International 181 (1), 1-80. https://doi.org/10.1111/j.1365-246X.2009.04491.X.

Freed A.M., Bürgmann R., Calais E., Freymueller J., Hreinsdóttir S., 2006. Implications of deformation following the 2002 Denali, Alaska, earthquake for postseismic relaxation processes and lithospheric rheology. Journal of Geophysical Research: Solid Earth 111 (B1), B01401. https://doi.org/10.1029/2005JB003894.

Goldin S.V., Timofeev V.Y., Ardyukov D.G., 2005. Fields of the earth's surface displacement in the Chuya earthquake zone in Gornyi Altai. Doklady Earth Sciences 405 (9), 1408-1413. 
Herring T.A., King R.W., McClusky S.C., 2006a. GAMIT Reference Manual, GPS analysis in MIT, Release 10.3. Department of Earth, Atmospheric, and Planetary Sciences, Massachusetts Institute of Technology, USA.

Herring T.A., King R.W., McClusky S.C., 2006b. GLOBK Reference Manual. Global Kalman filter VLBI and GPS analysis program. Release 10.3. Department of Earth, Atmospheric, and Planetary Sciences, Massachusetts Institute of Technology, USA.

International Seismological Centre, 2018. On-line Bulletin. Thatcham, United Kingdom, http://www.isc.ac.uk. http://doi.org/10.31905/D808B830.

Leskova E.V., Emanov A.A., 2013. Hierarchical properties of the tectonic stress field in the source region of the 2003 Chuya earthquake. Russian Geology and Geophysics 54 (1), 87-95. https://doi.org/10.1016/j.rgg.2012.12.008.

Mazurov B.T., 2007. The Study of Geodynamic Processes Based on Geodetic and Gravitational Parameters Modeling. Doctoral Thesis (Doctor of Geology and Mineralogy). Siberian State Academy of Geodesy, Novosibirsk, 255 p. (in Russian) [Мазуров Б.Т. Изучение геодинамических процессов на основе моделирования геодезических и гравитационных параметров: Дис. ... докт. техн. наук. Новосибирск: СГГА, 2007. 255 с.].

Okada Y., 1985. Surface deformation due to shear and tensile faults in a half-space. Bulletin of the Seismological Society of America 75 (4), 1135-1154.

Peltzer G., Rosen P., Rogez F., Hudnut K., 1998. Poroelastic rebound along the Landers 1992 earthquake surface rupture. Journal of Geophysical Research: Solid Earth 103 (B12), 30131-30145. https://doi.org/10.1029/98JB02302.

Pollitz F.F., 2003. Post-seismic relaxation theory on a laterally heterogeneous viscoelastic model. Geophysical Journal International 155 (1), 57-78. https://doi.org/10.1046/j.1365-246X.2003.01980.x.

Segall P., 2002. Integrating geologic and geodetic estimates of slip rate on the San Andreas fault system. International Geology Review 44 (1), 62-82. https://doi.org/10.2747/0020-6814.44.1.62.

Stacey F.D., 1969. Physics of the Earth. John Wiley \& Sons, New York, 324 p.

Toda S., Stein R.S., Sevilgen V., Lin J., 2011. Coulomb 3.3 graphic-rich deformation and stress-change software for earthquake, tectonic, and volcano research and teaching - user guide. U.S. Geological Survey Open-File Report 2011-1060, 63 p. Available from: https://pubs.usgs.gov/of/2011/1060/.

Turcotte D.L., Schubert G., 1982. Geodynamics: Application of Continuum Physics to Geological Problems. John Wiley \& Sons, New York, $464 \mathrm{p}$.

\section{Владимир Юрьевич Тимофеев}

докт. физ.-мат. наук, заведующий лабораторией

Институт нефтегазовой геологии и геофизики

им. А.А. Трофимука СО РАН

630090, Новосибирск, пр. Академика Коптюга, 3, Россия

e-mail: timofeevvy@ipgg.nsc.ru

\section{Дмитрий Геннадьевич Ардюков}

канд. физ.-мат. наук, с.н.с.

Институт нефтегазовой геологии и геофизики

им. А.А. Трофимука СО РАН

630090, Новосибирск, пр. Академика Коптюга, 3, Россия

e-mail: ardyukovdg@ipgg.nsc.ru
Vladimir Yu. Timofeev

Doctor of Physics and Mathematics, Head of Laboratory

A.A. Trofimuk Institute of Petroleum Geology and Geophysics, Siberian Branch of RAS

3 Academician Koptug ave., Novosibirsk 630090, Russia

Dmitriy G. Ardyukov

Candidate of Physics and Mathematics, Senior Researcher

A.A. Trofimuk Institute of Petroleum Geology and Geophysics,

Siberian Branch of RAS

3 Academician Koptug ave., Novosibirsk 630090, Russia 
V.Yu. Timofeev et al.: Modern movements of the crust surface in Gorny Altai...

\section{Антон Владимирович Тимофеев}

канд. физ.-мат. наук, н.с.

Институт нефтегазовой геологии и геофизики

им. А.А. Трофимука СО РАН

630090, Новосибирск, пр. Академика Коптюга, 3, Россия

e-mail: timofeevav@ipgg.nsc.ru

\section{Елена Валерьевна Бойко}

канд. физ.-мат. наук, н.с.

Институт нефтегазовой геологии и геофизики

им. А.А. Трофимука СО РАН

630090, Новосибирск, пр. Академика Коптюга, 3, Россия

e-mail: boykoev@ipgg.nsc.ru

\section{Anton V. Timofeev}

Candidate of Physics and Mathematics, Researcher

A.A. Trofimuk Institute of Petroleum Geology and Geophysics, Siberian Branch of RAS

3 Academician Koptug ave., Novosibirsk 630090, Russia

\section{Elena V. Boiko}

Candidate of Physics and Mathematics, Researcher

A.A. Trofimuk Institute of Petroleum Geology and Geophysics, Siberian Branch of RAS

3 Academician Koptug ave., Novosibirsk 630090, Russia 